\title{
Thalamus Controls Development and Expression of Arousal States in Visual Cortex
}

\author{
() Yasunobu Murata and ${ }^{-M a t t h e w ~ T . ~ C o l o n n e s e ~}$ \\ Department of Pharmacology and Physiology, and Institute for Neuroscience, George Washington University, Washington, DC 20037
}

Two major checkpoints of development in cerebral cortex are the acquisition of continuous spontaneous activity and the modulation of this activity by behavioral state. Despite the critical importance of these functions, the circuit mechanisms of their development remain unknown. Here we use the rodent visual system as a model to test the hypothesis that the locus of circuit change responsible for the developmental acquisition of continuity and state dependence measured in sensory cortex is relay thalamus, rather than the local cortical circuitry or the interconnectivity of the two structures. We conducted simultaneous recordings in the dorsal lateral geniculate nucleus (dLGN) and primary visual cortex (VC) of awake, head-fixed male and female rats using linear multielectrode arrays throughout early development. We find that activity in dLGN becomes continuous and positively correlated with movement (a measure of state dependence) on P13, the same day as VC, and that these properties are not dependent on VC activity. By contrast, silencing dLGN after P13 causes activity in $\mathrm{VC}$ to become discontinuous and movement to suppress, rather than augment, cortical firing, effectively reversing development. Thalamic bursting, a core characteristic of non-aroused states, emerged later, on P16, suggesting these processes are developmentally independent. Together our results indicate that cellular or circuit changes in relay thalamus are critical drivers for the maturation of background activity, which occurs around term in humans.

Key words: cortex; preterm; resting state; spontaneous activity; thalamus

\section{Significance Statement}

The developing brain acquires two crucial features, continuous spontaneous activity and its modulation by arousal state, around term in humans and before the onset of sensory experience in rodents. This developmental transition in cortical activity, as measured by electroencephalogram (EEG), is an important milestone for normal brain development and indicates a good prognosis for babies born preterm and/or suffering brain damage such as hypoxic-ischemic encephalopathy. By using the awake rodent visual system as a model, we identify changes occurring at the level of relay thalamus, the major input to cortex, as the critical driver of EEG maturation. These results could help understand the circuit basis of human EEG development to improve diagnosis and treatment of infants in vulnerable situations.

\section{Introduction}

The mature cerebral cortex continuously generates activity spontaneously, even at rest (Fox and Raichle, 2007). In primary sensory cortex, sensory input does not provide the major drive but rather modulates ongoing network dynamics (Fiser et al., 2004; Sakata and Harris, 2009). The function of this continuous background activity is an ongoing subject of study, but it is clearly

\footnotetext{
Received June 14, 2018; revised Aug. 13, 2018; accepted Aug. 21, 2018.

Author contributions: Y.M. wrote the first draft of the paper; Y.M. and M.T.C. edited the paper. Y.M. and M.T.C. designed research; Y.M. performed research; Y.M. contributed unpublished reagents/analytic tools; Y.M. and M.T.C. analyzed data.

This work was supported by NIH Grant R01 EY022730 (M.T.C.).

The authors declare no competing financial interests.

Correspondence should be addressed to Dr. Matthew T. Colonnese, Department of Pharmacology and Physiology, and Institute for Neuroscience, George Washington University, 2300 Eye Street Northwest, Washington, DC 20037. E-mail: colonnese@gwu.edu.

DOI:10.1523/JNEUROSCI.1519-18.2018

Copyright $\odot 2018$ the authors $\quad 0270-6474 / 18 / 388772-15 \$ 15.00 / 0$
}

both a target as well as effector of arousal and attention (Harris and Thiele, 2011; McCormick et al., 2015), including the generation of classically defined frequency bands observed by electroencephalography (EEG; Steriade and McCarley, 2005).

In contrast, the developing cortex exhibits long-lasting silent periods with very low spike activity (Khazipov and Luhmann, 2006). These silent periods last for up to several tens of seconds and are occasionally interrupted by oscillatory bursting activity (Ackman et al., 2012; Khazipov et al., 2013; Yang et al., 2016; Whitehead et al., 2017). In addition, early cortical activity is poorly organized by the behavioral state of animals and fails to show robust modulation by sleep and wakefulness (Gramsbergen, 1976; Scher, 2008; Seelke and Blumberg, 2008). Such discontinuous and largely state-independent activity prevails in most cortical areas during early development (Vanhatalo and Kaila, 2006), until the onset of sensory experience: near term in humans and eye-opening in the visual system of rodents (André et al., 2010; Colonnese and Phillips, 2018). This developmental transi- 
tion in cortical activity, as measured by EEG in human, is crucial for healthy brain development. Its presence indicates a good prognosis for babies born preterm and/or suffering severe brain damage such as hypoxic-ischemic encephalopathy (Holmes and Lombroso, 1993; van Rooij et al., 2005). Despite the scientific and clinical importance, the circuits necessary for development of continuous and state-dependent cortical activity remain to be understood.

The visual thalamus, lateral geniculate nucleus (LGN), transmits a majority of visual information from the retina to visual cortex (VC; Sherman and Guilery, 2013). Rodent dorsal LGN (dLGN) circuitry undergoes various developmental changes at the anatomical and synaptic levels (Huberman et al., 2008; Bickford et al., 2010; Hong and Chen, 2011; Grant et al., 2012; Brooks et al., 2013; Seabrook et al., 2013), suggesting that the thalamus could potentially impact cortical activity development. In adult rodents, activity and visual processing in VC is modulated in coordination with behavioral transitions from quiescence to moving (Niell and Stryker, 2010; Ayaz et al., 2013; Bennett et al., 2013; Polack et al., 2013; Fu et al., 2014; Lee et al., 2014; Vinck et al., 2015), potentially serving a model of cortical state regulation by behavioral engagement and arousal (Harris and Thiele, 2011). Multiple studies show that dLGN is similarly modulated by movement (Erisken et al., 2014; Usrey and Alitto, 2015; Williamson et al., 2015; but not Niell and Stryker, 2010), suggesting that state-dependent modulation of VC activity could arise in part from relay thalamus. However, it remains largely uncharacterized how dLGN activity develops in vivo and to what extent dLGN is necessary for maintaining and modulating mature VC activity at various developmental stages.

Here we investigate whether and to what degree the development of cortical activities described above are the result of circuit maturation in the thalamus or thalamocortical relationships. We address these questions in the visual system of awake, head-fixed rats by simultaneous recordings of visual thalamus and cortex using multielectrode arrays. We find that the visual thalamus plays a critical role for the onset and maintenance of continuous activity as well as for the emergence of adult-like modulation of cortical activity associated with movement. Our results provide a developmental time course of thalamocortical activity maturation in vivo and demonstrate the important thalamic contributions to cortical activity development.

\section{Materials and Methods}

In vivo electrophysiology. All experiments were conducted with approval from The George Washington University Institutional Animal Care and Use Committee, in accordance with the Guide for the Care and Use of Laboratory Animals (NIH). Long-Evans female rats (RRID: RGD_1302656) with litters at postnatal day (P)4 (birth = P0), or pregnant female rats at embryonic day 11-19, were acquired from Hilltop Lab Animals (Scottdale, PA) and housed one litter per cage on a $12 \mathrm{~h}$ light/ dark cycle. Both male and female pups were used for experiments. Eyelid opening occurred between $\mathrm{P} 13$ and $\mathrm{P} 14$. In vivo recording methods are as previously described (Murata and Colonnese, 2016). Topical lidocaine $(2.5 \%)$ and systemic Carprofen $(5 \mathrm{mg} / \mathrm{kg}$ ) were used for preoperative analgesia. To place the headplate, under isoflurane anesthesia ( $3 \%$ induction, $1-2 \%$ maintenance, verified by toe pinch), the scalp was resected, the skull was cleaned, and a stainless plate with a hole was placed so that the region over occipital cortex was accessible. The plate was fixed to the skull with dental cement. Pups were monitored for signs of stress after recovery from anesthesia. For recording, the animal was head-fixed, and the body was supported within a padded enclosure. For unweaned animals younger than P19, body temperature was monitored with a thermocouple placed under the abdomen and maintained at $34-36^{\circ} \mathrm{C}$ by heating pad placed under the body restraint. Body movement was de- tected using a piezo-based detector placed under the enclosure. Electrical activity of neck muscle was detected by electromyogram (EMG) from the ventral neck. For VC recording, the skull above the monocular primary visual cortex was thinned, and the monocular primary visual cortex was targeted with the following coordinates: $0.5-1.2 \mathrm{~mm}$ anterior from the lambda suture, and 2.5-3.0 (P5-P7), 2.8-3.3 (P9-P11), 3.0-3.5 (P13P14), 3.3-3.8 (P16-P26), or 3.5-4.0 (P42-P60) mm lateral from lambda. Coordinates for dLGN were $2.0-2.5 \mathrm{~mm}$ anterior and $3.0-3.5 \mathrm{~mm}$ lateral (P5-P7), 2.3-2.8 $\mathrm{mm}$ anterior and 3.3-3.8 mm lateral (P9-P11), 2.5-3.0 $\mathrm{mm}$ anterior and 3.5-4.0 $\mathrm{mm}$ lateral (P13-P14), or 3.0-3.5 $\mathrm{mm}$ anterior and 3.7-4.2 mm lateral (P16-P26), or 3.3-3.8 mm anterior and 3.8-4.3 $\mathrm{mm}$ lateral from the lambda (P42-P60). Extracellular activity was recorded using 32 channel single-shank, linear arrays (NeuroNexus). A combination of linear "edge" arrays with 100,50 , or $20 \mu \mathrm{m}$ separation or "Poly2" design of two parallel rows with $50 \mu \mathrm{m}$ separation were used. Electrodes were coated with DiI (Life Technologies) before insertion for histological verification of electrode location. For P5-P7 animals (before visual responsiveness) recordings were tentatively judged to be in dLGN or $\mathrm{VC}$ if they displayed prominent $1-5 \mathrm{~s}$ firing and elongated network silence indicative of retinal waves at this age (Hanganu et al., 2006). In animals older than P8, recording was initiated if flash-evoked (contralateral eye) firing on presumptive dLGN electrodes preceded VC. Four animals were not recorded for this reason. Postmortem reconstruction of the electrode tract was used to verify placement within central dLGN and monocular VC by reference to a developmental atlas (Khazipov et al., 2015). Three P5-P7 animals were not analyzed because the electrode was not located in the dLGN. $\mathrm{An} \mathrm{Ag} / \mathrm{AgCl}$ wire was placed over right frontal cortex ( $\sim 1 \mathrm{~mm}$ posterior and $3 \mathrm{~mm}$ lateral to bregma) as ground. Electrical signals were digitized using the Neuralynx Digital Lynx S hardware with Cheetah v5.6 software. dEEG signals were bandpass filtered between $0.1 \mathrm{~Hz}$ and $9 \mathrm{kHz}$, and digitized at $32 \mathrm{kHz}$. Cortical recordings were referenced to a contact site located in the underlying white matter. dLGN recordings were referenced to a contact just dorsal to dLGN. Multiunit activity (MUA) was extracted by threshold crossing of $-50 \mu \mathrm{V}$ following $300 \mathrm{~Hz}$ to $9 \mathrm{kHz}$ bandpass. Visual stimuli were provided by a $100 \mathrm{~ms}$ whole-field flash (100 lux) every $30 \mathrm{~s}$ to the contralateral eye on a background of low light ( $<1$ lux $)$.

For thalamic silencing, the dLGN electrode was removed after control recording, and 200-500 $\mathrm{nl}$ of $1 \mathrm{~mm}$ muscimol and 1\% Chicago Sky Blue in saline (Poulet et al., 2012) was injected using a Nanoject II (Drummond) at the same stereotaxic coordinates used for the dLGN recording. Recording began 10 min after injection. The injection site was confirmed postmortem to be located in dLGN and to not have invaded cortex. For VC silencing, after baseline recording, $2-3 \mu \mathrm{l}$ of APV ( $5 \mathrm{~mm}$ )/CNQX (2 $\mathrm{mM}$ ) in saline was applied to the burr hole used for VC recording, and recording restarted after $10 \mathrm{~min}$. VC silencing was confirmed by verifying the complete secession of firing in all layers of VC. Because dLGN and VC recordings were not aligned, we cannot be certain that the aligned portion of $\mathrm{VC}$ was completely inhibited by the treatment. However, the drug eliminated activity at all depths $(\sim 1.2 \mathrm{~mm})$ of VC before P14. Assuming a similar horizontal spread ( $2 \mathrm{~mm}$ diameter), inhibition will, at a minimum, affect all of monocular VC. Thus it is likely that activity is severely reduced throughout the relevant regions of VC. For postmortem analysis, animals were perfused with $4 \%$ paraformaldehyde in PBS, the brains sectioned by vibratome, and mounted with Fluoromount-G (Electron Microscopy Sciences). Images were acquired using a Zeiss DM6000 B microscope with a $10 \times$ objective.

Analysis. Neural signals were imported into MATLAB (RRID: SCR_001622). Spike-times and dEEG were downsampled to $1 \mathrm{kHz}$. Before analysis, six animals were eliminated for unstable baseline LFPs (periods of spontaneous fluctuation larger than the maximum amplitude of visual response) or spike activity ( $>20 \%$ change in total multiunit firing rate between the start and end of recording). The open-source Klustasuite was used for spike isolation, clustering, and manual curation (Rossant et al., 2016). A spike isolation "strong" threshold of 6 SD and "weak" threshold of 3 SD were used to minimize low-amplitude, unclusterable spikes (Colonnese et al., 2017). Initial clustering was evaluated for merging or splitting of clusters based on visual waveform analysis and similarity. After eliminating clusters composed of noise, clusters with 
A
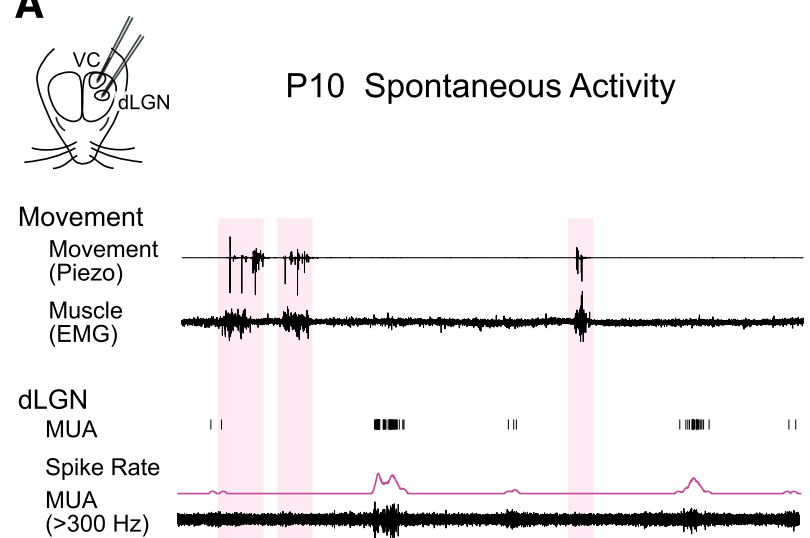

VC

MUA

Spike Rate

MUA

$(>300 \mathrm{~Hz})$

LFP
$(1-150 \mathrm{~Hz})$

Spectrogram

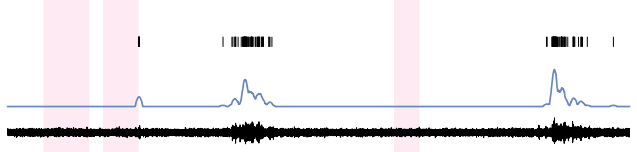

P10 Spontaneous Activity

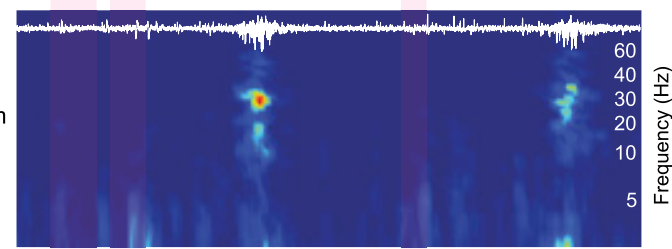

B

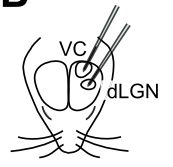

P13 Spontaneous Activity

Movement

Movement

(Piezo)

Muscle

(EMG)

dLGN

MUA

Spike Rate

MUA

$(>300 \mathrm{~Hz})$

VC

MUA

Spike Rate

MUA

$(>300 \mathrm{~Hz})$

LFP

$(1-150 \mathrm{~Hz})$

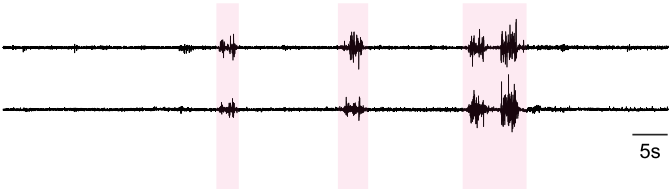

$5 s$

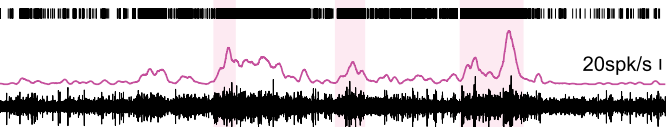

$50 \mu \mathrm{V}$

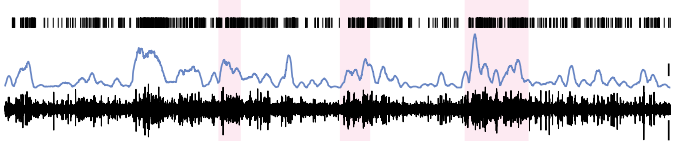

Spectrogram

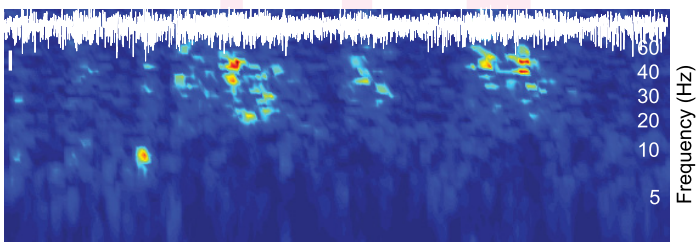

Figure 1. Simultaneous emergence of continuous spontaneous activity modulated during movement in dLGN and VC before the onset of vision. $A$, Representative spontaneous activity in dLGN and VC of a P10 rat. Simultaneous extracellular recordings were performed from the visual thalamus (dLGN) and the VC in awake, head-fixed Long-Evans rats. MUA ( $>300 \mathrm{~Hz}$ ), spike rate of dLGN and VC layer 4, VC LFP (1-150 Hz) and its spectrogram are shown. Periods of movements are detected by thoracic movement (piezo) and neck muscle (EMG) and marked by light red shades. In both $\mathrm{dLGN}$ and VC, long-lasting silent periods with very low spike activity are occasionally interrupted with oscillatory spindle-burst activity, largely during periods of quiescence. Note dLGN and VC recordings are not aligned in topographic space; the offset in dLGN and VC bursts likely reflect the spread of a retinal wave across thalamocortex. $\boldsymbol{B}$, Representative spontaneous activity in dLGN and VC of a $\mathrm{P} 13$ rat. Both thalamic and cortical spike activities become continuous. Spike rates are higher during movement in $\mathrm{dLGN}$ and VC, where movement is further associated with increased beta and gamma band power in the LFP. Bars represent 5 s, 20 spikes/s and $50 \mu \mathrm{V}$.

poor reduction of the autocorrelation near $0 \mathrm{~ms}$ and/or clear superposition of two or more distinct waveforms were marked as multiunit clusters. The remaining, potentially single-unit, clusters were evaluated for inclusion as good single-units if the interspike interval refractory violations ( $<1 \mathrm{~ms}$ ) accounted for $<0.1 \%$ of spikes. All clusters were assigned a primary contact localization by determining the location of the maximum amplitude in the mean waveform.

Cortical L4 was identified in each recording as the channel with the earliest negative deflection and the fastest spike response in the mean visual evoked response as previously described (Berzhanskaya et al., 2017). For dLGN, visual-responsive regions were identified by $100 \mathrm{~ms}$ flashes to the contralateral eye. The dLGN channel with the earliest spike response to contralateral visual stimuli was used for detailed analysis of multiunit spike rates, continuity, and modulation. For P5-P7, because of the lack of visual response at this age, cortical L4 was identified as the channel with the largest spike response during spontaneous spindlebursts; likewise, the recording site in dLGN with the strongest spike activity during spindle-bursts was used for detailed analysis.

For all analyses, activity for each animal was calculated from the entirety of a continuous $20 \mathrm{~min}$ baseline control period and from a $20 \mathrm{~min}$ period following manipulation. For spectral analysis in VC, LFP spectra were obtained over a fixed window $(2 \mathrm{~s}$ for spontaneous and $0.3 \mathrm{~s}$ for visually evoked response) by the multitaper method using the freely available Chronux package (Mitra and Bokil, 2007) with taper parameters $[3,5]$. Movement periods were defined by the presence of EMG or piezo signal with a root mean square signal $>2 \mathrm{SD}$ above baseline for $>300 \mathrm{~ms}$. This duration was chosen by observation to separate spontaneous twitching during sleep from volitional motion. Quiet periods between moment lasting $<500 \mathrm{~ms}$ were considered as part of the movement period. For spectral analysis, if motion lasted $<2 \mathrm{~s}$ (but longer than the minimum) a $2 \mathrm{~s}$ window centered on the movement was analyzed. A minimum of $10 \mathrm{~s}$ without movement was required to define a quiescent period. To avoid residual and anticipatory arousal effects (Vinck et al., 2015), spiking and spectral analysis was taken beginning $3 \mathrm{~s}$ from the end of the last moving period and ending $1 \mathrm{~s}$ from the beginning of next. Animal mean spectra were calculated by averaging spectral windows in each "state". To reduce the effect of the $1 / f$ relationship, mean multitaper spectra were multiplied by frequency. For dLGN, animal mean MUA spectra were obtained by calculating the Fourier transform of the autocorrelation of MUA. Time-series spectra for dLGN MUA (Figs. 1, 3, and 7) were calculated by filtering the MUA time series with a Gaussian window $(5 \mathrm{~ms} \alpha)$ and applying the multitaper method as above. For both signals, the frequency axis was resampled on a log scale to equalize the representation of high and low frequencies and reduce the multiple-comparisons problem. For normalization, frequency power at each band was divided by the mean power. Spike continuity is the inverse of the proportion of time occupied by interspike intervals $>500 \mathrm{~ms}$ in MUA. Movement modulation was calculated as $\left(\mathrm{FR}_{\mathrm{mov}}-\mathrm{FR}_{\text {quies }}\right) /$ $\mathrm{FR}_{\text {quies }}$. For visual responses, onset time was calculated as the median of the first spike following stimulus for all trials, offset time was the time when mean firing rate fell $<20 \%$ of the peak firing rate. Duration was the time between onset and offset.

Experimental design and statistical analysis. Both male and female of Long-Evans rats were used. No formal sorting or randomization of subjects was applied, and experiments and analysis were not blind to age or treatment. The number of animals included in the experiments is included in the figure legends.

Mean \pm SEM and each data point are reported. Hypothesis tests were conducted using nonparametric methods when $n<10$. Wilcoxon signed rank test was used for pairwise comparison. One-way ANOVA was used 
Table 1. Summary data for spike and spectral results

\begin{tabular}{|c|c|c|c|c|c|c|c|c|c|c|}
\hline \multirow{2}{*}{\multicolumn{2}{|c|}{$\frac{\text { Figure }}{\text { Multiunit }}$}} & \multirow[t]{2}{*}{ Metric } & \multirow[t]{2}{*}{ P5-P6 } & \multirow[t]{2}{*}{ P9-P11 } & \multirow[t]{2}{*}{ P13-P14 } & \multirow[t]{2}{*}{ P16-P19 } & \multirow[t]{2}{*}{ P21-P26 } & \multirow[t]{2}{*}{ P42-P60 } & \multirow[t]{2}{*}{ ANOVA for age } & \multirow[t]{2}{*}{$p$ value } \\
\hline & & & & & & & & & & \\
\hline $2 A 1$ & VC & Spikes per second & $0.23 \pm 0.08$ & $0.95 \pm 0.49$ & $8.46 \pm 1.41$ & $10.99 \pm 2.11$ & $18.01 \pm 5.78$ & $21.64 \pm 7.18$ & $F_{(5,30)}=17.3$ & $=10^{-7}$ \\
\hline $2 A 2$ & LGN & Spikes per second & $2.29 \pm 0.56$ & $6.32 \pm 0.94$ & $19.06 \pm 5.74$ & $24.75 \pm 5.01$ & $25.83 \pm 3.3$ & $56.27 \pm 9.88$ & $F_{(5,30)}=30.1$ & $=10^{-10}$ \\
\hline $2 B 1$ & VC & Continuity & $0.02 \pm 0.01$ & $0.03 \pm 0.02$ & $0.57 \pm 0.07$ & $0.7 \pm 0.07$ & $0.82 \pm 0.06$ & $0.9 \pm 0.03$ & $F_{(5,30)}=28.2$ & $=10^{-9}$ \\
\hline $2 B 2$ & LGN & Continuity & $0.14 \pm 0.03$ & $0.25 \pm 0.03$ & $0.8 \pm 0.06$ & $0.95 \pm 0.02$ & $0.96 \pm 0.01$ & $1.0 \pm 0.0$ & $F_{(5,30)}=149$ & $=10^{-19}$ \\
\hline $2 C 1$ & VC & Change during movement & $-26.3 \pm 5.6 \% *$ & $-50.3 \pm 8.5 \% *$ & $35.4 \pm 11.9 \%$ & $26.8 \pm 6.1 \% *$ & $24.3 \pm 7.6 \% *$ & $44.3 \pm 19.3 \%^{*}$ & $F_{(5,30)}=12.2$ & $=10^{-5}$ \\
\hline $2 C 2$ & LGN & Change during movement & $-25.2 \pm 6.7 \%^{*}$ & $-23.6 \pm 3.7 \% *$ & $87.5 \pm 26.9 \% *$ & $79.9 \pm 15.7 \% *$ & $105.6 \pm 13.6 \% *$ & $83.2 \pm 17.7 \%^{*}$ & $F_{(5,30)}=13.8$ & $=10^{-6}$ \\
\hline $3 C$ & VC & $\begin{array}{l}\text { Spike rate change after } \\
\text { LGN silencing }\end{array}$ & & $-78.6 \pm 3 \%^{*}$ & $-60.7 \pm 7.1 \% *$ & $-55.5 \pm 2.6 \% *$ & $-58.7 \pm 7.3 \%^{*}$ & $-59.6 \pm 7.5 \% *$ & $F_{(4,25)}=2.39$ & $=0.0775$ \\
\hline $3 D$ & VC & $\begin{array}{l}\text { Continuity change after } \\
\text { LGN silencing }\end{array}$ & & $-94.2 \pm 1.2 \%^{*}$ & $-86.1 \pm 3.2 \% *$ & $-75.5 \pm 6.2 \% *$ & $-69.1 \pm 3.6 \% *$ & $-58.7 \pm 10.6 \% *$ & $F_{(4,25)}=5.51$ & $=0.0025$ \\
\hline $3 E$ & VC & $\begin{array}{l}\text { Change during movement } \\
\text { (before LGN silence) }\end{array}$ & & $-35.8 \pm 9.3 \%^{*}$ & $11.5 \pm 6.2 \%$ & $19.8 \pm 4 \%^{*}$ & $24.3 \pm 7.6 \%{ }^{*}$ & $44.3 \pm 19.3 \%^{*}$ & $F_{(4,25)}=7.74$ & $=0.0003$ \\
\hline $3 E$ & VC & $\begin{array}{l}\text { Change during movement } \\
\text { (after LGN silence) }\end{array}$ & & $-49.9 \pm 10.8 \% *$ & $-56.7 \pm 9.2 \% *$ & $-47.9 \pm 10.4 \% *$ & $-37 \pm 11.1 \% *$ & $-36.1 \pm 6 \%^{*}$ & $F_{(4,25)}=0.82$ & $=0.5252$ \\
\hline $7 E$ & VC & On Latency, ms & & $246.7 \pm 16.3$ & $95.2 \pm 4.6$ & $55.2 \pm 4.4$ & $39.8 \pm 1.3$ & $27.2 \pm 2.7$ & $F_{(4,25)}=127.6$ & $=10^{-15}$ \\
\hline $7 E$ & LGN & On Latency, ms & & $136.5 \pm 15.1$ & $67.2 \pm 4.3$ & $42 \pm 3.8$ & $29.7 \pm 1.1$ & $15.8 \pm 1$ & $F_{(4,25)}=43.2$ & $=10^{-10}$ \\
\hline $7 F$ & VC & Off Latency, ms & & $560.5 \pm 46.2$ & $146.5 \pm 8.7$ & $94.3 \pm 4.9$ & $83.8 \pm 5.3$ & $82.8 \pm 2.1$ & $F_{(4,25)}=94.4$ & $=10^{-13}$ \\
\hline $7 F$ & LGN & Off Latency, ms & & $683.2 \pm 39.6$ & $157.5 \pm 10.1$ & $115.7 \pm 12.1$ & $89 \pm 7.1$ & $85.5 \pm 2.8$ & $F_{(4,25)}=176.5$ & $=10^{-17}$ \\
\hline $7 G$ & VC & Duration, ms & & $313.8 \pm 44.3$ & $51.3 \pm 7.6$ & $39.2 \pm 6.2$ & $44.1 \pm 5.1$ & $55.7 \pm 4.2$ & $F_{(4,25)}^{(4,23)}=33.8$ & $=10^{-9}$ \\
\hline $7 G$ & LGN & Duration, ms & & $546.7 \pm 39.5$ & $90.3 \pm 11.5$ & $73.7 \pm 14.3$ & $59.3 \pm 7.9$ & $69.7 \pm 3.4$ & $F_{(4,25)}=113.9$ & $=10^{-14}$ \\
\hline $7 H$ & VC & On delay (VC-LGN), ms & & $110.2 \pm 9.4$ & $28 \pm 2.9$ & $13.2 \pm 1.4$ & $10.1 \pm 1.2$ & $11.3 \pm 2.2$ & $F_{(4,25)}=87.2$ & $=10^{-13}$ \\
\hline 71 & LGN & Off delay (VC-LGN), ms & & $122.7 \pm 29$ & $11 \pm 6.5$ & $21.3 \pm 9.8$ & $5.2 \pm 6.5$ & $2.7 \pm 2.4$ & $F_{(4,25)}=12.6$ & $=10^{-5}$ \\
\hline \multicolumn{11}{|c|}{ Single unit } \\
\hline $5 C$ & LGN & No. of single units & $11.5 \pm 2.7$ & $14.5 \pm 2$ & $32 \pm 4.6$ & $43 \pm 2.9$ & $36.8 \pm 3.5$ & $41.7 \pm 3.3$ & $F_{(5,30)}=17.6$ & $=10^{-7}$ \\
\hline $5 D$ & LGN & Spikes in SU clusters, \% & $54.7 \pm 12.3 \%$ & $41.7 \pm 3.8 \%$ & $61 \pm 2 \%$ & $71.9 \pm 6 \%$ & $69.4 \pm 4.3 \%$ & $74.3 \pm 3.6 \%$ & $F_{(5,30)}=2.48$ & $=0.054$ \\
\hline $5 E$ & LGN & Spike amplitude, $\mu \mathrm{V}$ & $65.8 \pm 4.5$ & $82 \pm 10.4$ & $95 \pm 3.5$ & $114.6 \pm 5.7$ & $91.6 \pm 10.3$ & $130.6 \pm 6.1$ & $F_{(5,30)}=10.0$ & $=10^{-4}$ \\
\hline $5 F$ & LGN & Spike width, ms & $0.74 \pm 0.02$ & $0.73 \pm 0.02$ & $0.76 \pm 0.01$ & $0.72 \pm 0.02$ & $0.57 \pm 0.02$ & $0.51 \pm 0.01$ & $F_{(5,30)}=37.82$ & $=10^{-11}$ \\
\hline $5 G 1$ & LGN & Spikes per second & $0.49 \pm 0.04$ & $0.9 \pm 0.13$ & $1.35 \pm 0.09$ & $1.43 \pm 0.12$ & $2.13 \pm 0.19$ & $3.18 \pm 0.2$ & $F_{(5,30)}=46.1$ & $=10^{-12}$ \\
\hline $5 G 2$ & LGN & Spikes per second & $0.51 \pm 0.04$ & $0.92 \pm 0.07$ & $1.33 \pm 0.08$ & $1.44 \pm 0.08$ & $2.12 \pm 0.12$ & $3.18 \pm 0.2$ & $F_{(5,1701)}=51.5$ & $=10^{-47}$ \\
\hline $5 H 1$ & LGN & Continuity & $0.06 \pm 0.01$ & $0.08 \pm 0.01$ & $0.14 \pm 0.01$ & $0.14 \pm 0.01$ & $0.23 \pm 0.02$ & $0.31 \pm 0.02$ & $F_{(5,30)}=45.6$ & $=10^{-12}$ \\
\hline $5 H 2$ & LGN & Continuity & $0.06 \pm 0.01$ & $0.08 \pm 0.01$ & $0.13 \pm 0.01$ & $0.14 \pm 0.01$ & $0.23 \pm 0.01$ & $0.32 \pm 0.02$ & $F_{(5,1701)}=52.39$ & $=10^{-47}$ \\
\hline $5 / 1$ & LGN & Change during movement & $-29.4 \pm 5.7 \%^{*}$ & $-22.2 \pm 4.2 \% *$ & $61.9 \pm 13.7 \%^{*}$ & $89.9 \pm 14.5 \% *$ & $67.3 \pm 9.7 \% *$ & $48.2 \pm 8.8 \% *$ & $F_{(5,30)}=24.0$ & $=10^{-8}$ \\
\hline $5 / 2$ & LGN & Change during movement & $-28.2 \pm 12.2 \%^{*}$ & $-22.9 \pm 6 \% *$ & $63.6 \pm 4.2 \% \%^{*}$ & $86.6 \pm 3.4 \% *$ & $64.6 \pm 3.7 \% *$ & $50.8 \pm 4 \% *$ & $F_{(5,1701)}=50.74$ & $=10^{-46}$ \\
\hline 601 & LGN & Spikes in bursts (movement) & $0.4 \% \pm 0.1 \%$ & $0.5 \% \pm 0.3 \%$ & $0.7 \% \pm 0.1 \%$ & $1 \% \pm 0.1 \%$ & $1.2 \% \pm 0.2 \%$ & $1.4 \% \pm 0.2 \%$ & $F_{(5,30)}=4.48$ & $=0.0036$ \\
\hline 602 & LGN & Spikes in bursts (quiescence) & $0.6 \% \pm 0.1 \%$ & $0.8 \% \pm 0.3 \%$ & $1.3 \% \pm 0.5 \%$ & $8.9 \% \pm 0.4 \%$ & $8.1 \% \pm 1.4 \%$ & $9.2 \% \pm 1.6 \%$ & $F_{(5,30)}=22.4$ & $=10^{-8}$ \\
\hline \multicolumn{11}{|c|}{ Spectral bands (Permutation test) } \\
\hline \multirow[t]{2}{*}{$2 D$} & VC & $\begin{array}{l}\text { Frequencies decreased during } \\
\text { movement, } \mathrm{Hz}\end{array}$ & $7.5-8.9$ & $8.2-22.9$ & $2.1-6.3$ & $1.7-11.5$ & $2.7-17.7$ & $1.4-17.1$ & & \\
\hline & & $\begin{array}{l}\text { Frequencies increased during } \\
\text { movement, } \mathrm{Hz}\end{array}$ & & & $16.2-49.6$ & $35.2-45.4$ & $27.1-58.9$ & $41.7-49.6$ & & \\
\hline \multirow[t]{2}{*}{$2 E$} & VC & $\begin{array}{l}\text { Negative correlation with LGN } \\
\text { spike rate, } \mathrm{Hz}\end{array}$ & & & $1.5-6.3$ & $1.5-14.9$ & $2.5-8.9$ & $1.5-13.7$ & & \\
\hline & & $\begin{array}{l}\text { Positive correlation with LGN } \\
\text { spike rate, } \mathrm{Hz}\end{array}$ & & & $13.7-98.6$ & $25.0-98.6$ & $25.0-98.6$ & $29.60 .7-98.6$ & & \\
\hline \multirow[t]{2}{*}{$3 F$} & VC & $\begin{array}{l}\text { Frequency decreased w/movement, } \\
\mathrm{Hz} \text { (before silence) }\end{array}$ & & $8.9-22.9$ & $1.7-8.9$ & $3.8-13.7$ & $2.7-17.7$ & $1.5-14.9$ & & \\
\hline & & $\begin{array}{l}\text { Frequency increased w/movement, } \\
\mathrm{Hz} \text { (before silence) }\end{array}$ & & & $16.2-41.8$ & $32.3-45.5$ & $27.1-49.6$ & $41.8-49.6$ & & \\
\hline $3 G$ & VC & $\begin{array}{l}\text { Frequency decreased w/movement, } \\
\mathrm{Hz} \text { (after silence) } \\
\text { Frequency increased w/movement, } \\
\mathrm{Hz} \text { (after silence) }\end{array}$ & & $1.5-16.2$ & $1.5-10.6$ & $1.6-3.5$ & $1.5-4.9$ & $1.9-7.5$ & & \\
\hline \multirow[t]{2}{*}{$6 C$} & LGN & $\begin{array}{l}\text { Interspike interval decreased } \\
\text { w/movement, ms }\end{array}$ & & & & $1-4$ & $1-3$ & $1-3$ & & \\
\hline & & $\begin{array}{l}\text { Interspike interval increased } \\
\text { w/movement, } \mathrm{ms}\end{array}$ & & & $48-51$ & $19-79$ & $17-51$ & $8-17$ & & \\
\hline
\end{tabular}

*Significantly different from 0 .

for all tests of age dependence, and post hoc test (Tukey HSD) used to examine differences between specific age groups. Descriptive statistics and results of the ANOVA are reported in Table 1. Significant differences by post hoc test $(p<0.05)$ are reported as asterisks on the relevant figure. $P$ values $<0.001$ are rounded to nearest power of 10 . Spectra were examined at each frequency for significant difference using nonparametric permutation tests corrected for multiple comparisons by the method of Cohen (Cohen, 2014) with $p<0.01$. The exact frequency or interval ranges detected are reported in Table 1, and referenced as needed for clarity in the Results. All tests were performed in MATLAB. The number of animals is reported in the figures (it is 6/group unless otherwise noted).

\section{Results}

We conducted extracellular recording simultaneously from the visual thalamus, dLGN, and from the monocular primary VC of awake, head-fixed Long-Evans rats from P5 to P60 (Fig. 1). We used multielectrode linear-array to record from multiple sites of different depth. All recordings were performed in unanesthetized 
head-fixed animals because even very light anesthesia eliminates most spikes and oscillations during early development (Colonnese and Khazipov, 2010; Ackman et al., 2012). Body movement was detected using a piezo-based detector placed under the enclosure, while the nuchal EMG was recorded from the ventral neck. Spontaneous alternation between movement and quiescence has emerged as a robust method to measure the cortical effects of arousal and engagement (Harris and Thiele, 2011). Absence of movement theoretically can include multiple arousal states, including deep slow-wave sleep, quiet wakefulness, quiet arousal, and rapid eye movement sleep, that can be differentiated by pupil diameter, eyelid closure, and EEG in adults. However monitoring of pupil and eyelid status as well as EEG cannot be used consistently over the age ranges examined here (JouvetMounier et al., 1970; Seelke and Blumberg, 2010; Vinck et al., 2015), requiring a more consistent albeit low-resolution metric for state dependence. Likewise, a treadmill or similar apparatus was not used to monitor locomotion because it is not a practical method for weeks one and two when they must be externally thermoregulated. For this initial exploration of thalamocortical activity development we have limited the quantification of state dependence to the behavioral transition between quiescence and active movement during head-fixed body restraint, which is qualitatively similar to transitions between quiescence and running in mice (Berzhanskaya et al., 2017). In our setup quiescence largely consisted of quiet wakefulness, with a greater proportion occupied by quiet (non-REM) sleep in younger animals. Active/REM sleep is rare in head-fixed rodents unless special and age-specific efforts are made to elicit it (Karlsson and Blumberg, 2003; Yüzgeç et al., 2018).

Consistent with previous results (Colonnese and Khazipov, 2010; Ackman et al., 2012; Colonnese et al., 2017), until P11, the VC has long-lasting silent periods with no spiking activity in any layer (Fig. 1A). Locally, these silent periods last for tens of seconds but are occasionally interrupted by spontaneous oscillatory activity, called spindle-bursts or spontaneous-activity-transients, which are the cortical response to spontaneous retinal waves (Hanganu et al., 2006). Spindle-bursts contain powerful 20-30 $\mathrm{Hz}$ oscillations that last up to several seconds (Colonnese and Khazipov, 2010). Also consistent with previous reports (Murata and Colonnese, 2016), dLGN showed a similar pattern of long silent periods interrupted with $20-30 \mathrm{~Hz}$ oscillations. At these young ages, animal movement and neuronal activity were not robustly visibly correlated in either dLGN or VC. After P13, spontaneous spiking and LFP activity was largely continuous in both VC and dLGN (Fig. 1B). At these ages, movement was visibly consistently associated with an increase in MUA in dLGN and $\mathrm{VC}$ as well as with decreases in the large amplitude, slow frequencies of the LFP.

\section{Simultaneous development of continuity and movement-modulation in thalamus and cortex}

To quantify the developmental changes in spontaneous activity in these two structures we recorded simultaneously in dLGN and VC from age groups designed to reflect the major developmental stages: P5-P7 (stage 2 retinal waves); P9-P11 (stage 3 retinal waves); P13-P14 (after development of continuous activity in VC); P16-P19 (pre-critical period); P21-P26 (critical period); and P42-P60 (near adult). The percentage of time spent moving was similar in all age groups $(n=6$ each; P5-P7 $11.7 \pm 2.4 \%$, $\mathrm{P} 9-\mathrm{P} 1114.1 \pm 3.0 \%, \mathrm{P} 13-\mathrm{P} 1412.1 \pm 2.6 \%, \mathrm{P} 16-\mathrm{P} 1910.3 \pm$ $3.1 \%$, P21-P26 14.6 \pm 4.1\%, P46-P60 $8.8 \pm 3.2 \%$, ANOVA for age: $\left.F_{(5,30)}=0.50, p=0.77\right)$.
We first measured the statistics of firing rate and continuity across all behavioral states. Spontaneous MUA firing-rate in the layer 4 of $\mathrm{VC}$ and in dLGN develop in close parallel, with increases of nearly an order of magnitude increase between P5-P6 and P13-P14, more than two-thirds of the increase occurring between P9-P11 and P13-P14. By contrast in the week after P13-P14 MUA firing rates increased by $<1.3$-fold, with no significant changes between adjacent age groups (Fig. 2A; Table 1). We measured the continuity of activity as the proportion of time in which at least two spikes occurred with an interval of $500 \mathrm{~ms}$, approximately the smallest naturally occurring down-state in head-fixed rats (Colonnese, 2014). Spike continuity in VC and dLGN also both increase by $>10$-fold between P5-P6 and P13P14, with the only significant differences between adjacent groups occurring between P9-P11 and P13-P14. dLGN continuity was statistically unchanged after P13-P14, whereas VC continuity further increased by 1.2 -fold by P16-P19 and remained unchanged thereafter (Fig. 2B). Thus, VC and dLGN follow similar developmental trajectories for spike rate and continuity, suggesting that changes in dLGN may drive those occurring in VC.

We next examined how spike-modulation associated with movement emerges in thalamocortical circuits during development. Spike rate is reduced during movement in rat VC (Mukherjee et al., 2017) during the second postnatal week, although mice show increased firing during movement in L4, $1 \mathrm{~d}$ after eye-opening (Hoy and Niell, 2015). The specific timing of this switch not been examined in the same species under similar conditions, and has not been examined in dLGN for either species. We found that spike rates in both VC and dLGN significantly decreased during movement periods before P11. After P13 we observed significant movement-associated increases in spike rates in dLGN, which did not change significantly thereafter (Fig. 2C2). In VC, spike rates show a trend toward increase during movement at P13-P14, which is statistically significant at all ages after P16 (Fig. 2C1).

Next, we examined the frequency modulation of the VC LFP by movement during development. At P5-P7 and P9-P11, spectral power during quiescence largely accumulated in a single (or dual resonance) peak centered at $7-8 \mathrm{~Hz}$ at $\mathrm{P} 5-\mathrm{P} 6$ and $20 \mathrm{~Hz}$ at $\mathrm{P} 9-\mathrm{P} 11$, reflecting the dominant effect of retinal wave-driven spindle-burst oscillations (Fig. 2D). During movement, spontaneous LFP spectra maintained this same frequency distribution, though power in the spindle-burst frequency band was significantly reduced $(7.5-8.9 \mathrm{~Hz}$ at $\mathrm{P} 5-\mathrm{P} 6$ and $8.2-22.9 \mathrm{~Hz}$ at P9-P11), suggesting a general suppression of activity during movement rather than a qualitatively different cortical state. After P13, the transition from quiescence to movement was accompanied by large-scale reorganization of the frequency distribution of cortical activity. Broad beta and gamma power $(16.2-49.6 \mathrm{~Hz})$ became increased during movement at P13-P14 (Fig. 2D). The oscillation frequency of movement-associated modulation becomes narrower for the next few weeks until it was restricted to the gamma frequency range at P42-P60 (41.7-49.6 $\mathrm{Hz}$ ), consistent with previously reported experience-dependent development of cortical gamma oscillations (Chen et al., 2015; Hoy and Niell, 2015). In addition, power in lower frequencies $(<10 \mathrm{~Hz})$ was first significantly augmented during quiescence beginning at P13-P14 (Fig. 2D), and this augmentation remained consistent throughout the older ages. Next, we analyzed the correlation between dLGN firing and VC LFP throughout development. Correlation between dLGN spike rate and VC LFP spectral power shows that positive correlation in the high-frequency range and negative correlation in the low-frequency range appear 
A1

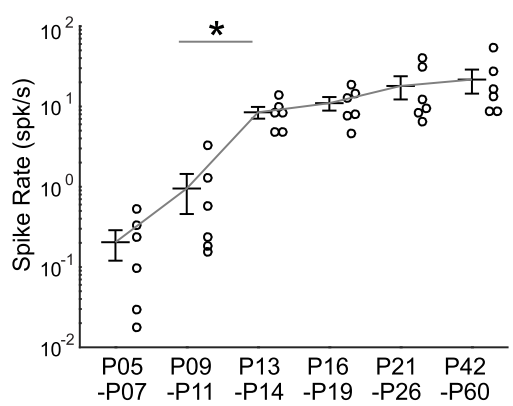

A2

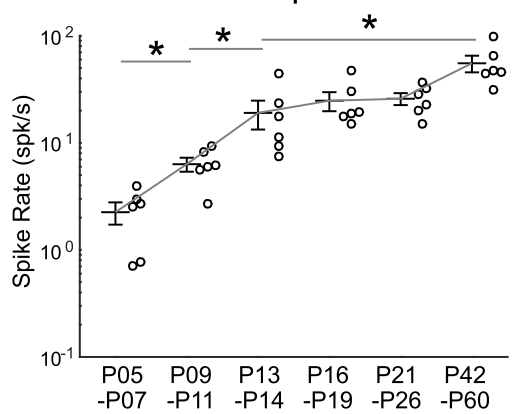

B1

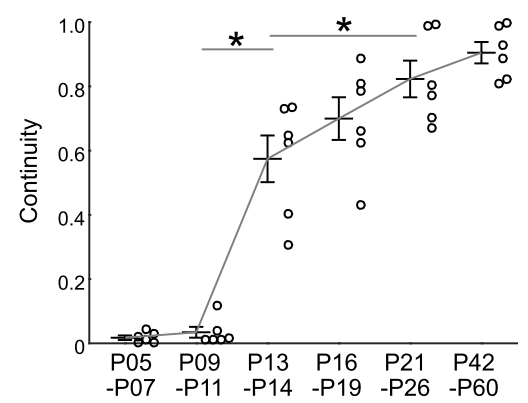

B2 dLGN Spike Continuity

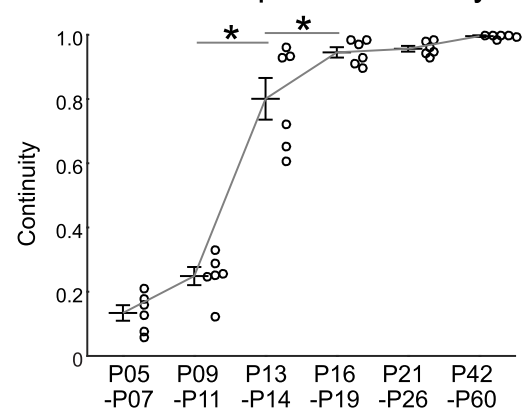

C1

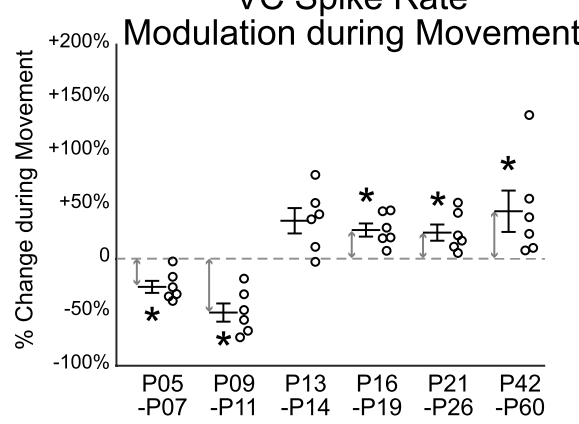

D VC LFP Spectra
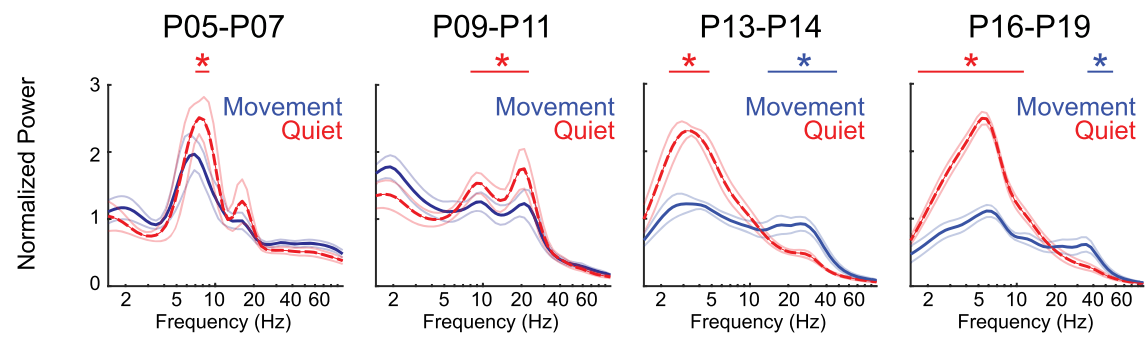

C2

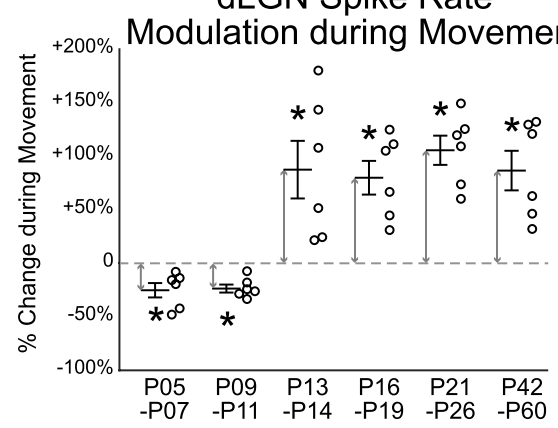

\section{E Correlation of VC LFP Spectra and dLGN Spike-Rate}

P05-P07

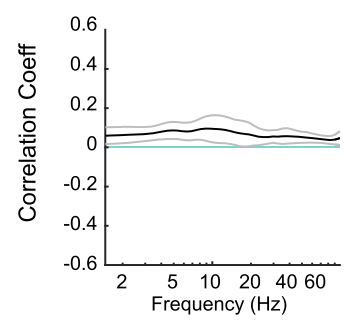

P09-P11

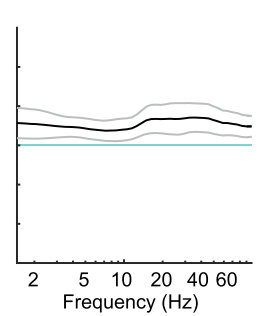

P13-P14

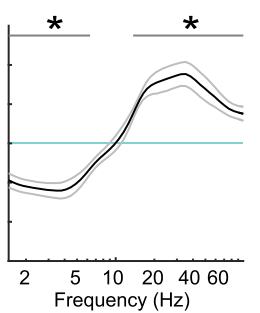

P16-P19

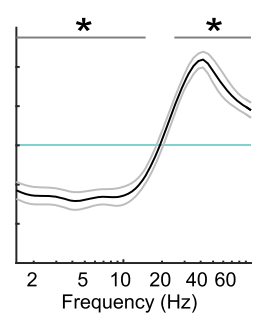

P21-P26

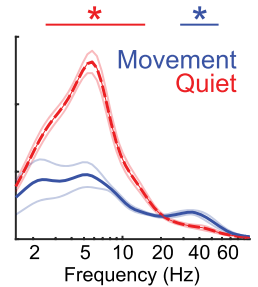

$\mathrm{P} 42-\mathrm{P} 60$

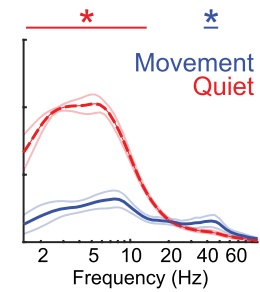

Figure 2. Continuous activity, spike rate, and modulation during movement develop simultaneously in thalamus and cortex. A, Spike rate of VC (A1) and dLGN (A2) increases throughout development. Circles show multiunit cortical layer $4(\boldsymbol{A} \mathbf{1})$ and dLGN $(\boldsymbol{A 2})$ spike rates from each animal taken from all conditions (quiet and moving). Line and error bars depict mean \pm SEM from $n=$ 6 animals in each age group. Asterisk line shows result of post hoc test following one-way ANOVA for age $(p<0.05)$. Only the shortest significance is shown for clarity (e.g., P9 -P11 is also different from P16, P21, and P42 groups). B, Continuity of MUA in L4VC (B1) and dLGN (B2) increases throughout development, largely between P11 and P13. C, MUA L4VC and dLGN firing-rates switch from negatively to positively correlated with movement between P11 and P13. Percentage change of VC $(C 1)$ and dLGN $(C 2)$ spike rate during movement relative to quiescence is shown at each age (asterisk marked arrows show significant difference from zero $(p=0.031)$ by one-sample Wilcoxon signed rank test. $\boldsymbol{D}$, Adult-like modulation of the VC LFP during movement emerges at P13. Population mean ( $n=6$ each) VC LFP spectra during movement (blue, solid line) and quiescence (red, dashed line) are shown for each age group. Thin lines show SEM. Frequency ranges with significant increase during movement are marked by blue bars; during quiescence by red bars (permutation test, ${ }^{*} p<0.05$ ). $\boldsymbol{E}$, Adult-like correlation between VC LFP power and dLGN firing-rate emerge after P13. Frequency ranges significantly different from zero are marked by black bars (permutation test, ${ }^{*} p<0.01$ ). 
after P13 (Fig. 2E), demonstrating that dLGN firing becomes tightly associated with the pattern of VC LFP frequency distribution just before the onset of visual experience.

In total, these results suggest that visual thalamus and cortex acquires adult-like movement-associated changes of cortical state, which include augmentation of spike rates in both structures and shifts in the LFP patterns driven by increases in thalamic firing, as early as P13, with only subtle additional changes over the next weeks.

\section{dLGN is necessary for continuity and adult-like movement-modulation in VC after P13}

The results described above suggest that the changes in thalamic behavior are responsible for the developmental acquisition of continuity and adult-like state-switching in association with movement in VC. To examine the degree to which dLGN contributes to VC activity and its modulation, we pharmacologically silenced dLGN by local injection of $1 \mathrm{~mm}$ Muscimol and 1\% Chicago Sky Blue dye after recording under control condition (Poulet et al., 2012). Only animals in which postrecording histology revealed the injection site to be centered in dLGN were included in the analysis. dLGN silencing was further validated by the lack of visual response in VC. Because animals younger than P8 do not show visual response (Colonnese et al., 2010), we investigated animals older than P9. Recordings from hippocampus directly under VC did not show an effect of drug infusion on spike activity $(n=6$, total firing rate change after infusion: $+2.9 \% \pm 11.1 \%$, Wilcoxon signed rank test, $p=0.68$ ), showing that muscimol did not effectively spread $>1.5 \mathrm{~mm}$ from the injection site. However, parts of the nearby lateral posterior nucleus (pulvinar), with direct projections to VC (Roth et al., 2016), could also be implicated in blockade.

Thalamic silencing decreased VC spike rates and continuity at all ages and changed the direction of movement associated spikerate modulation in VC after P13 (Fig. $3 A, B$ ). Silencing reduced VC spike rates by $>50 \%$ at all ages examined (Fig. $3 C$ ), with no significant differences between ages (Table 1). Silencing also reduced VC spike continuity at all ages (Fig. 3D); this effect of silencing grew weaker with age, from a maximal effect of $94 \%$ reduction P9-P11 and minimal effect of 58\% P46-P60. These results show that $\mathrm{VC}$ requires intact dLGN activity to maintain its spike rate and continuity not only in early development, but also in adults.

Next, we analyzed whether thalamic silencing affects VC spike-rate modulation associated with movement. Silencing significantly reduced firing-rate increases observed during movement after at all ages P13-P14 and older, but not at P9-P11 (Fig. $3 E$; Table 1). Interestingly, thalamic silencing made $\mathrm{VC}$ at all ages resemble $\mathrm{P} 9-\mathrm{P} 11$, as firing rates were significantly reduced during movement, rather than increased as before the silencing. In addition, silencing changed the VC LFP frequency distribution during quiescence, and disrupted the state changes associated with movement (Fig. $3 F, G$ ). In particular, beta and gamma frequency bands were no longer augmented during movement compared with quiescence (Fig. $3 F, G$ ). Significant reductions in low-frequency bands were still observed following thalamic silencing, suggesting a cortical origin for these rhythms and their state dependence. These results suggest the crucial role of relay thalamus in the generation of high-frequency spiking and field potential activity in VC during movement.

This role of dLGN to drive continuity and movement dependence may result from changes in thalamus and its inputs, or result from changes in the corticothalamic loop. Therefore, to determine whether $\mathrm{VC}$ is required for $\mathrm{dLGN}$ activity modulation, we pharmacologically silenced VC by local application of the glutamate antagonist APV and CNQX. The effective silencing of $\mathrm{VC}$ at these ages was confirmed by the complete loss of VC spikes. We have previously shown that VC silencing decreases dLGN activity at P9-P11 but increases it at P13-P14, suggesting the cortical feedback changes its role from amplification to suppression of thalamic activity between P11 and P13 (Murata and Colonnese, 2016; Fig. 3). Here we present the result of cortical silencing on movement associated firing rate changes. At P9P11, dLGN MUA firing rates are decreased by $39.3 \pm 8.9 \%$ during movement before VC silencing, and $35.8 \pm 5.2 \%$ after (Fig. $4 A ; n=6$, Wilcoxon signed rank test for difference from 0 , before and after $p=0.031$; difference between control and VC: $p=$ 0.219 by Wilcoxon). By contrast, at P13-P14, dLGN spikes-rate increased during movement $80.5 \pm 21.1 \%$ before and $35.6 \pm$ $17.4 \%$ after VC silencing (Fig. 4B; $n=6$, Wilcoxon test for difference from 0 , before and after $p=0.031$ ). The difference between the between the two conditions was not significant (Wilcoxon, $p=0.813$ ). These results show that although VC amplifies dLGN spike activity before P11 and suppresses it after P13 (Murata and Colonnese, 2016), VC is not required for movement-associated modulation of dLGN spike rate at any age. Together, the results above suggest that the changes in visual thalamic circuits, not in cortical, are responsible for acquisition of continuous movement-correlated activity.

\section{Thalamic developmental changes occur in single units}

Next, we examined the development of dLGN activity at the neuron level by isolating presumptive single units from a multielectrode array (Fig $5 A, B$ ). The mean number of clusters that could be categorized as reliable single-units in each animal more than tripled between P9-P11 and P16-P19 (Fig. 5C; Table 1 for all descriptive stats), but the proportion of total recorded spikes that were placed in good clusters was not significantly different between ages (Fig. 5D), suggesting spike sorting using the masked EM algorithm was of similar quality among ages examined (Rossant et al., 2016). Mean spike amplitude gradually increased with age (Fig. 5E; lowest P5-P7 $65.8 \pm 4.5 \mu \mathrm{V}$; highest P42-P60 $130.6 \pm 6.1 \mu \mathrm{V}$ ), whereas spike width is gradually decreased between P13-P14 (0.76 $\pm 0.01 \mathrm{~ms})$ and P42-P60 (0.51 $\pm 0.01 \mathrm{~ms}$; Fig. $5 F)$.

The single-unit recordings show a similar, though more gradual, development of spike rate and continuity as observed for the MUA (Fig. 5G,H; Table 1). Mean animal firing rate showed a significant effect of age, increasing gradually from $0.49 \pm 0.04$ spikes/s at P5-P7 to $3.18 \pm 0.2$ spikes/s at P42-P60, with significant changes between adjacent age groups at $\mathrm{P} 5-\mathrm{P} 7$ versus $\mathrm{P} 9-$ P11 and P9-P11 versus P13-P14 (Fig. 5G1; $n=6$ /group). Mean spike rate for all neurons showed a similar pattern (Fig. 5G2; for this and all single-unit analyses: $n=6$ animals per group and P5-P7 69, P9-P11 87, P13-P14 192, P16-P19 258, P21-P26 221, $\mathrm{P} 42-\mathrm{P} 60250$ neurons). Mean animal continuity was $0.06 \pm 0.01$ at P5-P7, increasing significantly to $0.31 \pm 0.02 \mathrm{P} 42-\mathrm{P} 60$, but no adjacent age groups were significantly different until the P21-P26 and P41-P60 groups (Fig. 5H1). Examination of the means for all neurons was similar (Fig. 5H2). In contrast to spike rate and continuity, for which the parameters developed more gradually for single units compared with multiunits, the developmental changes in spike-rate associated with movement developed as a step-function between P9-P11 and P13-P14 (Fig. 5I). Mean animal single-unit movement-modulation (Fig. 5I1) was significantly negative at P5-P7 $(-29 \pm 6 \%)$ and P9-P11 $(-22 \pm 4 \%)$. 
A

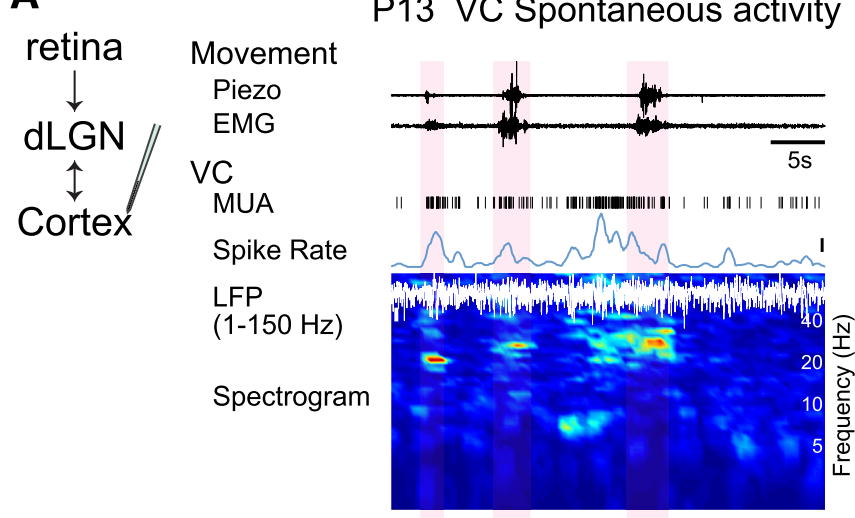

B

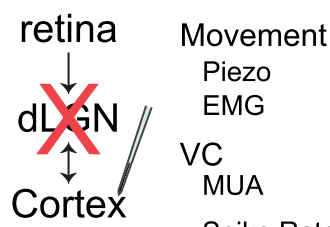

Spike Rate

LFP

$(1-150 \mathrm{~Hz})$

Spectrogram

\section{After Thalamic Silencing}

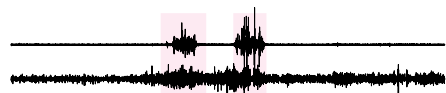

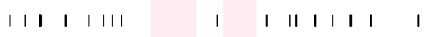

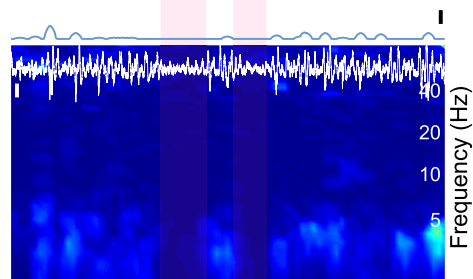

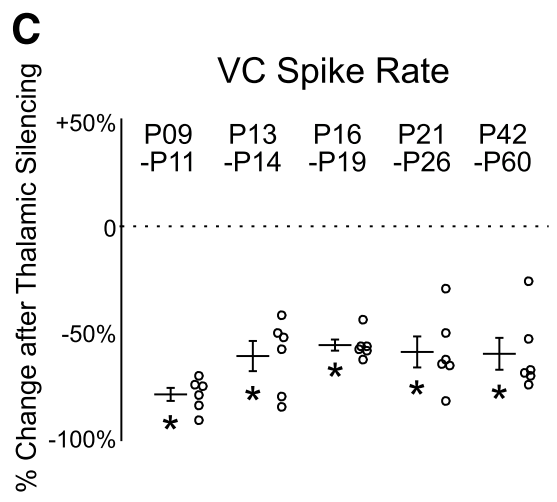

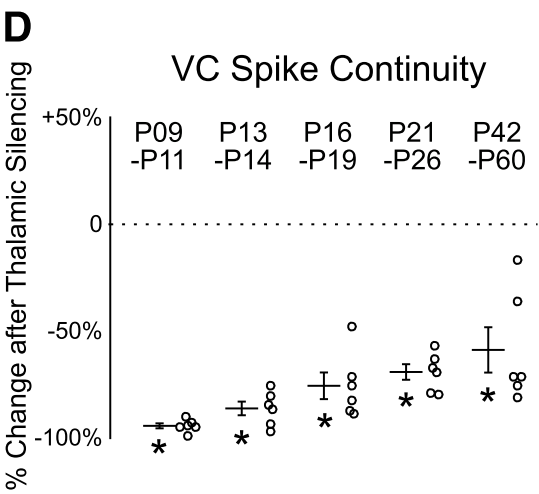

E

VC Spike Rate

Modulation during Movement

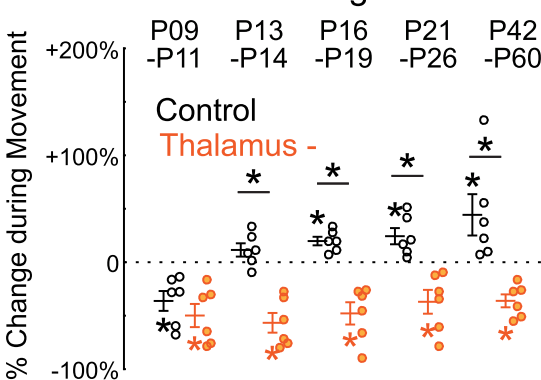

VC LFP Modulation during Movement

\section{F Before Thalamic silencing}
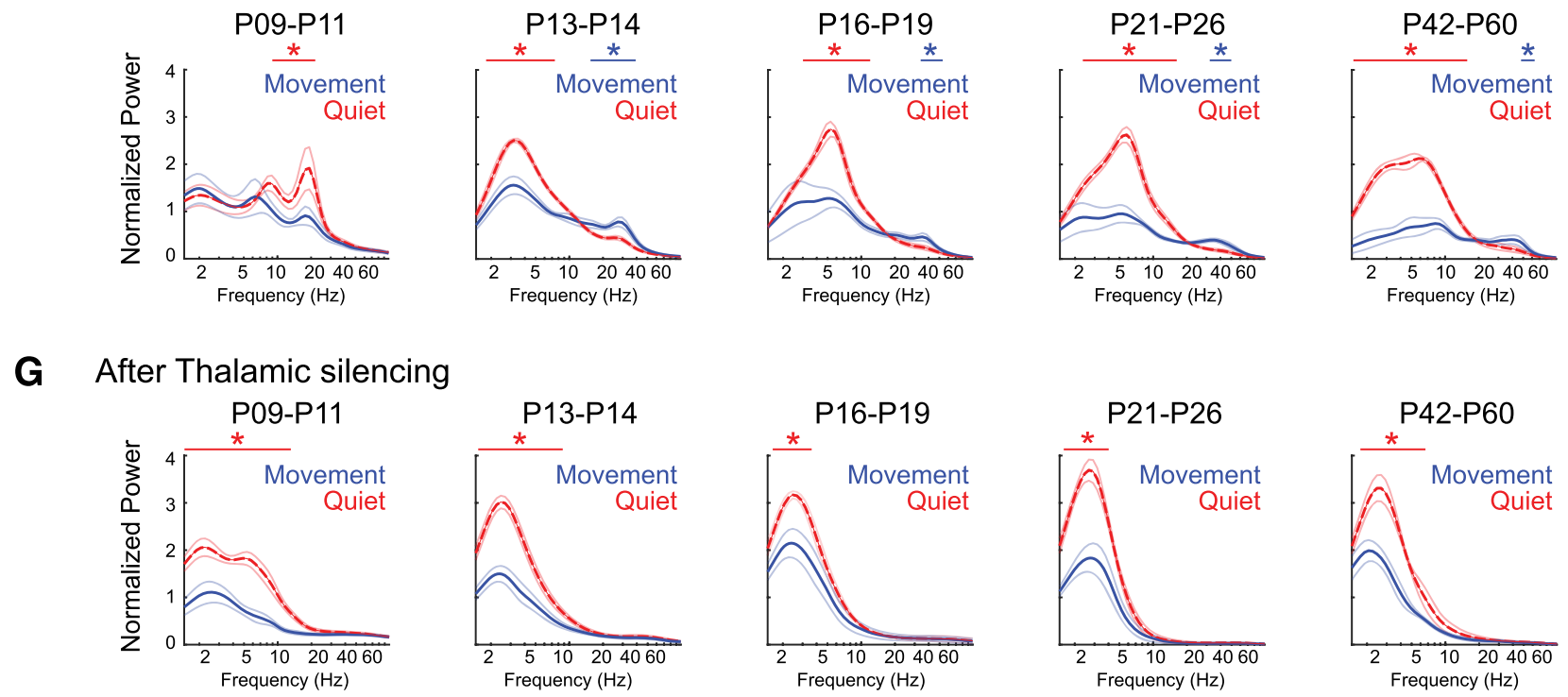

Figure 3. dLGN is required for continuous visual cortical activity modulated during movement after P13. $\boldsymbol{A}, \boldsymbol{B}$, Representative VC spontaneous activity before $(\boldsymbol{A})$ and after thalamic silencing $(\boldsymbol{B})$ at $P 13$. VC MUA, spike rate, LFP, and its spectrogram are shown. Movement periods are marked by light red shades. Thalamus was silenced with local injection of $1 \mathrm{~mm}$ muscimol into dLGN after control recording. After thalamic silencing, VC spikes decreased and became discontinuous, and VC LFP lost beta-gamma band activity during movement. Bars represent $5 \mathrm{~s}, 10$ spikes/s, and $100 \mu \mathrm{V}$. C, D. dLGN is the major contributor to VC spike activity throughout development. Percentage changes of VC L 4 MUA spike rate $(\boldsymbol{C})$ and continuity $(\boldsymbol{D})$ after thalamic silencing at each age $(n=6$ each; Wilcoxon signed rank test for difference from pre-silencing, $\left.{ }^{*} p=0.031\right)$. , Thalamic silencing causes suppression of V( spiking during movement. After thalamic silencing, V( spikes are negatively modulated during movement at all ages examined, a pattern usually observed only before P9-P11 in intact animals. Percentage changes of dLGN spike rate during movement relative to quiescence are shown for baseline (Control, black open circle) and following thalamic silencing (Thalamus, orange filled circle) at each age ( $n=6$ each; Wilcoxon signed rank test for difference ( $p=0.031$ ) from zero ( ${ }^{*}$ on mean) and difference between control and thalamus (*on horizontal bar). $\boldsymbol{F}, \mathbf{G}$, Thalamic silencing alters VC LFP frequency distribution and its modulation during movement. VC LFP spectra during movement (blue) and quiescence (red) before (F) and after thalamic silencing $(\boldsymbol{G})$ are shown at each age. The augmentation of beta-gamma power during movement after $P 13$ is eliminated by thalamic silencing, whereas increases in lower frequency power during quiescence remain ( $n=6$ for each, horizontal line shows range of significant frequencies modulated during movement (permutation test, ${ }^{*} p<0.05$ ). 


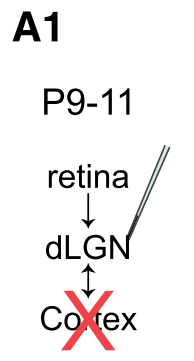

A2 dLGN Spike Rate
Modulation during Movement

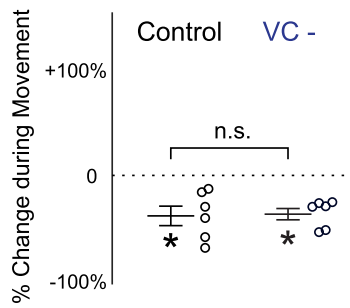

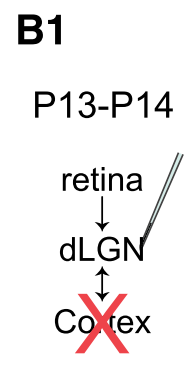

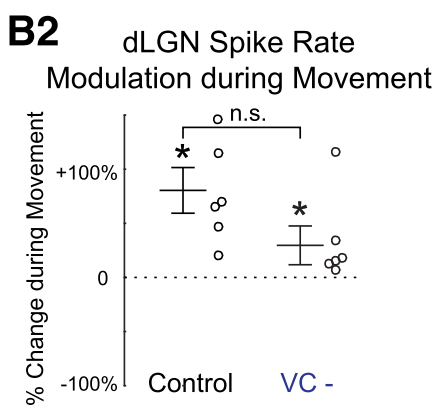

Figure 4. dLGN spike-rate modulation during movement is not significantly altered by VC silencing. $\boldsymbol{A}$, VC silencing does not significantly alter dLGN MUA rate changes observed during movement at P9-P11. VC was pharmacologically silenced by local application of the glutamate receptor antagonist APV and CNQX following baseline recording. At P9 -P11, dLGN spike rate is decreased during movement, and this movement-associated change is not significantly altered by VC silencing. [ $n=6$ for each; Wilcoxon signed rank test for difference from zero ( ${ }^{*} 0$ m mean) or for control vs VC silenced (horizontal bar); ${ }^{*} p=0.031$, n.S.: not significant]. $B$, At P13-P14, dLGN spike rate is increased during movement, and this movement-associated change in activity is not significantly modified by VC silencing $(n=6)$.

At all ages P13-P14 and older, movement was associated with significantly increased firing (between $48 \%$ and $67 \%$ increases). The mean movement change for all neurons was similar (Fig. 5I2) to the animal means.

During states of behavioral quiescence, thalamic neurons produce rapid bursts of spikes that likely contribute to the changes in cortical rhythms and sensory responses during inattentive states (Llinás and Steriade, 2006). We investigated the development of thalamic bursting and its relationship to cortical activity development by analyzing the distribution of interspike intervals of dLGN single units during movement and quiescence. We first examined the spike intervals separately for moving and quiescence at each age group by calculating the distribution for all intervals ( $1 \mathrm{~ms}$ bins) in a group. The interval distributions (Fig. $6 A, B)$ show clear shifts over age. At P5-P7 and P9-P11, the interval distributions were dominated by a low and highfrequency peaks that correspond to the structure of spindlebursts at these ages (Murata and Colonnese, 2016), but did not change much between movement and quiescence. Beginning with the P13-P14 group, difference between moving and quiescent periods emerged, as quiescence became associated with a peak in the distribution below intervals of $5 \mathrm{~ms}$, first appeared unimodal before becoming bimodal by P21-P26. To analyze the changes associated with movement statistically, we constructed a separate distribution using a logarithmically increasing bin size and first calculating interval distributions for each animal on which to perform a permutation analysis $(p<0.01)$ to determine intervals with statistically significant changes in occurrence between movement and quiescence (Fig. 6C). No significant difference was observed at P5-P7 or P9-P11. At P13-P14 we observed an increase in the proportion of intervals $48-51 \mathrm{~ms}$ during movement. At P16-P19 and above we observed a continued increase in longer intervals during movement as well as an increase in very short ( $<4 \mathrm{~ms}$ ) intervals during quiescence.

Very short $(<4 \mathrm{~ms})$ interspike intervals are defined as thalamic bursting in adults (Weyand et al., 2001; Steriade and McCarley, 2005). Thus, we next analyzed bursting activity in dLGN. Bursts are defined as at least two spikes with $4 \mathrm{~ms}$ or shorter interspike intervals following a $100 \mathrm{~ms}$ or longer silent period (Weyand et al., 2001). No more than $1.4 \%$ of spikes were part of a burst during movement periods at any age (Fig. 6D1). During quiescence the proportion of spikes in bursts increased from $1.3 \pm 0.5 \%$ at P13-P4 to $8.9 \pm 0.4 \%$ at P16-P19 (Fig. 6D2). Age groups below P13-P14 did not significantly differ from each other in burst proportion, and all were different from age groups
P16-P19 and above. Likewise, older animals differ significantly from the younger groups, but not each other. These results show that significant bursting activity appears in dLGN by P16, a few days after the thalamic and cortical acquisition of movement associated modulation, suggesting that movement-associated modulation of firing rate and bursting develop independently in thalamus.

\section{Thalamocortical visual response and transmission mature similarly to spontaneous activity}

Last, we quantified development of thalamocortical transmission by analyzing thalamic and cortical responses to the whole-field visual stimulation. Because animals younger than P8 do not show visual responses, we examined animals older than P9 and gave $100 \mathrm{~ms}$ whole-field visual stimuli on the contralateral eye through the closed (until P13) or opened eyelid (after P14).

Before P11, light flashes evoked slow-onset, long-lasting, high-amplitude responses that are typically composed of two distinct phases; an initial response containing gamma oscillation followed by a secondary response containing beta oscillation (Colonnese et al., 2010). dLGN MUA shows a similar biphasic spectral response as VC (an example is shown in Fig. 7A; more quantitative analysis is shown by Murata and Colonnese, 2016). After P13, the same light flashes evoked more adult-like visual response, consisting of a fast-onset and short-lasting response without secondary activation in both structures (Fig. 7B).

We calculated developmental changes in the onset and offset latency to determine what portion of these changes observed in cortex are mirrored in dLGN. Population mean poststimulus spike rate histogram for $\mathrm{dLGN}$ and VC were constructed, and each age showed qualitatively similar developmental profiles between these two structures (Fig. 7C,D). In particular, both structures change from long-duration responses to short, peaked responses between P9-P11 and P13-P14. Quantitative analysis of the population averages for response on and off latency, as well as total response duration, shows that visual responses in both $\mathrm{VC}$ and dLGN mature mainly between P11 and P13 (Fig. 7E-G). Off-latency and duration significantly declined between P9-P11 and P13-P14, but not thereafter, whereas on-latency also showed significant reductions between P13-P14 and P21-P26 and P42$\mathrm{P} 60$. The latency between dLGN onset and VC onset matured along the same pattern, significantly decreasing between P9-P11 and P13-P14 but not after, suggesting an improvement in thalamocortical transmission at the time of the state transition (Fig. $7 H$ ). To examine potential thalamic contributions to the 
A

P10 dLGN Spontaneous Activity

Single-unit

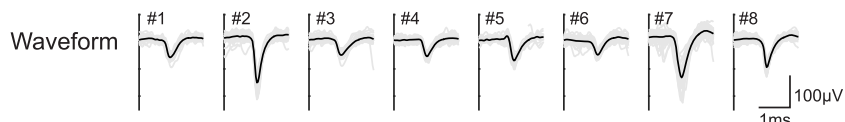

Spikes

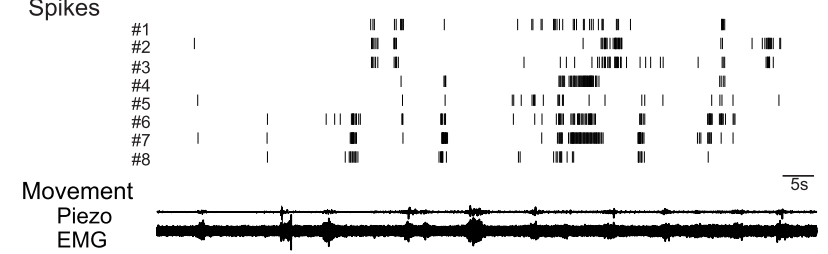

B

\section{P14 dLGN Spontaneous Activity}

Single-unit

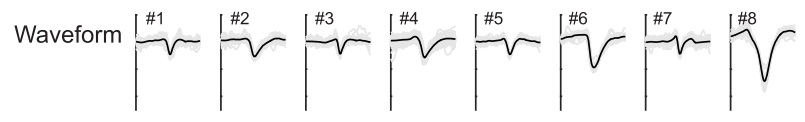

Spikes

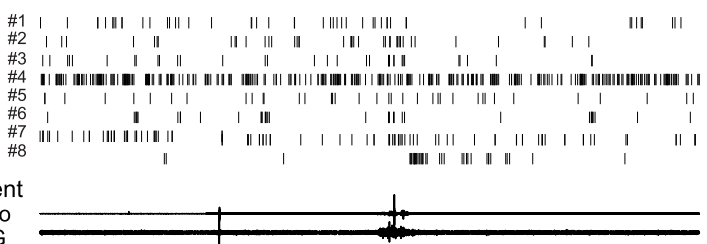

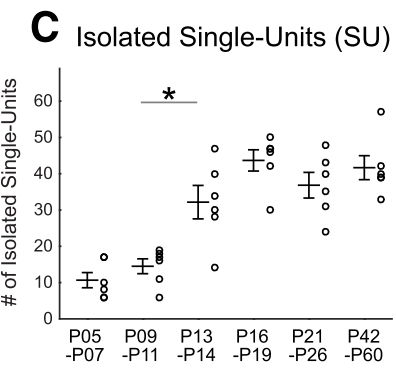
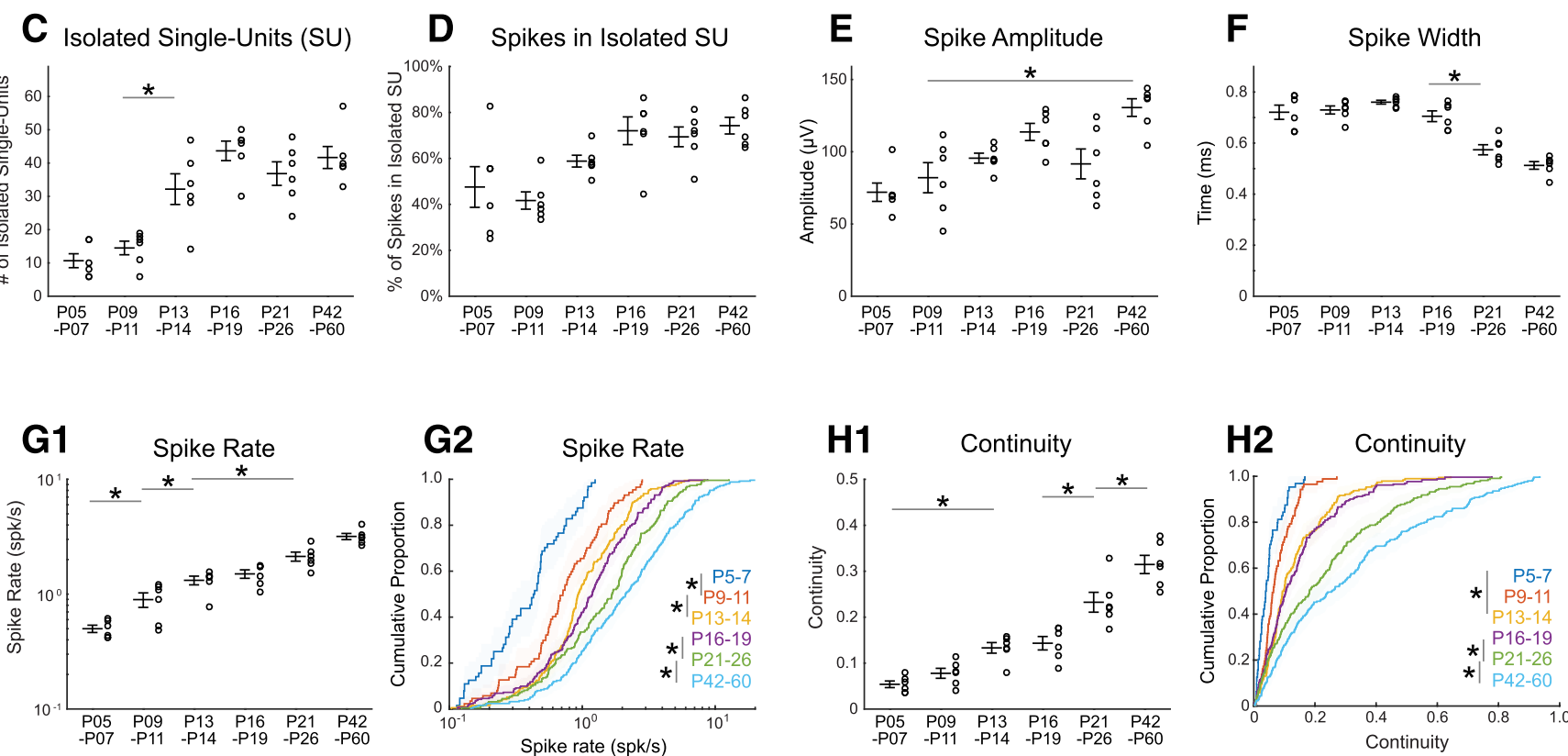

I1

Spike Rate

Modulation during Movement

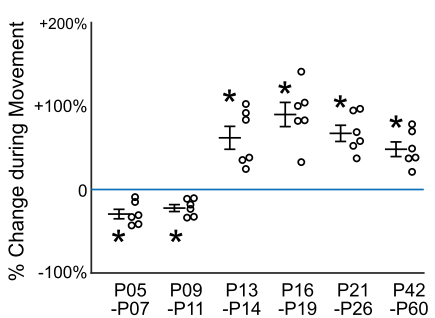

12

\section{Spike Rate}

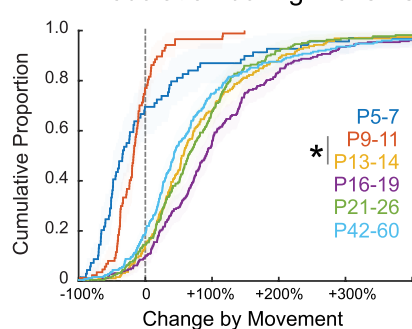

Figure 5. Development of thalamic single-unit behavior. $\boldsymbol{A}, \boldsymbol{B}$, Representative single units (SUs) isolated from multielectrode array recordings in dLGN of awake rats at P10 (A) and P14 ( $\boldsymbol{B})$. Waveforms and raster plot of representative eight SUs are shown at each age. $(-F$, Spike-sorting characteristics by developmental age. The number of identified SUs $(\boldsymbol{C}$, percentage of total spikes assigned to SUs $(\boldsymbol{D})$, spike amplitude $(\boldsymbol{E})$, and spike width $(\boldsymbol{F})$ for each age. $\boldsymbol{G}, \mathrm{dLGN} \mathrm{SU}$ spike rate increases gradually during development. dLGN SU spike rate is shown as animal means $(\boldsymbol{G 1} ; n=$ 6 each) and cumulative distribution for all units (G2; $n=69,87,192,258,221,250$, respectively). G1, G2, Asterisk bars show shortest significant pairs identified by post hoc test following ANOVA for effect of age; ${ }^{*} p<0.05$. $\boldsymbol{H}, \mathrm{dLGN}$ SU continuity increases during development. Statistics as for G. I, dLGN SU spike rates become positively modulated during movement after P13. Statistics as for $\mathbf{G}$, but for $\mathbf{I}$ asterisk denotes Wilcoxon signed rank test for difference from zero; $p=0.031$.

shortening of the visual responses between P9-P11 and P13-P14 we examined the offset latency between dLGN and VC. Previously results have indicated a rapid increase in feedforward inhibition driven by retinal axons in dLGN (Ziburkus et al., 2003; Dilger et al., 2011), by thalamocortical axons in VC (Colonnese,
2014) and by corticothalamic feedback to dLGN (Murata and Colonnese, 2016), all of which could contribute to the shortening. Surprisingly VC stops firing before dLGN at all ages (Fig. 7I) even though there was a significant drop in the off-latency between P9-P11 and P13-P14, the same day as the shortening. This 


\section{dLGN Interspike Interval}

A During Movement P05-P07
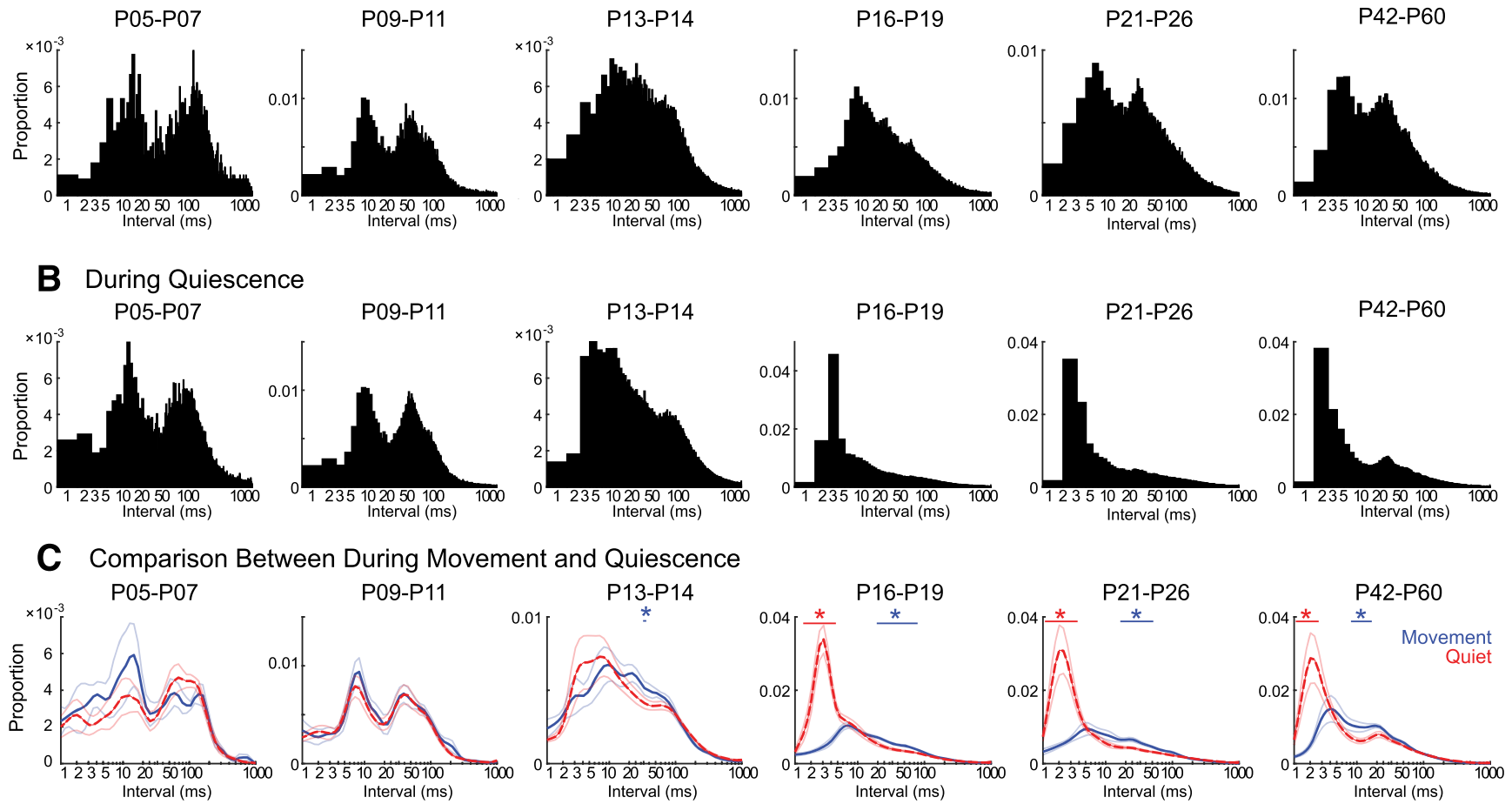

\section{dLGN spikes associated with bursts}
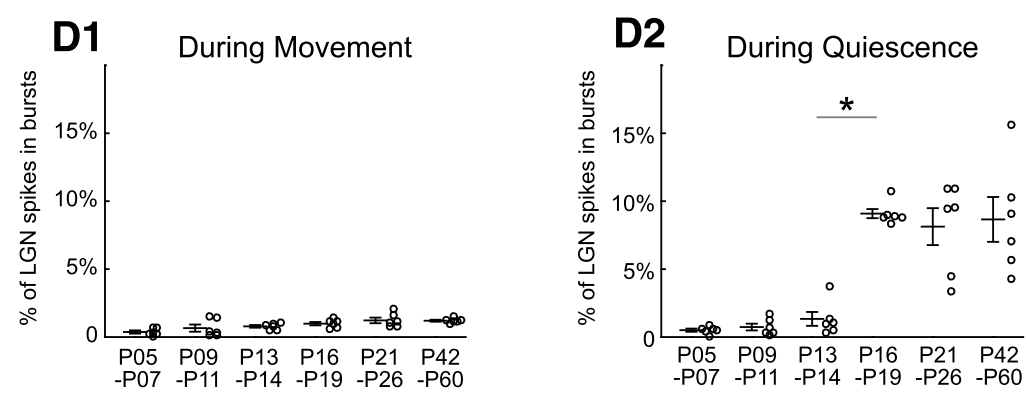

Figure 6. Developmental emergence of bursting in dLGN in vivo. $\boldsymbol{A}, \boldsymbol{B}$, Distribution of interspike intervals for all dLGN single-units during movement $(\boldsymbol{A})$ and quiescence $(\boldsymbol{B})$ by age group. One millisecond interval bins; $n=69,87,192,258,221,250$ neurons from 6 animals in each group. Notably, interspike intervals $<4$ ms become prominent during quiescence after P16.C, Animal mean interspike intervals during movement and quiescence. Mean and SEM of $n=6$ animals per group. Horizontal bars show significant decrease (red) and increase (blue) during movement (permutation test, $\left.{ }^{*} p<0.01\right)$. D, Percentage of spikes in bursts during movement (D1) and quiescence (D2) by age group. Frequent bursting occurs only during quiescence in $\mathrm{dLGN}$ and only after P16 $(n=6$ for each, ANOVA, horizontal bar shows shortest significant difference; ${ }^{*} p<0.01$ ).

suggests that inhibition in VC, in addition to shortening of dLGN responses, is a contributor to the visual response changes occurring on P12. Together our results suggest that thalamic and cortical visual responses and transmission mature simultaneously with the changes in spontaneous activity $\sim \mathrm{P} 13$.

\section{Discussion}

In this study, we provide a comprehensive developmental profile for activity in VC and dLGN using simultaneous recordings in unanesthetized rats. Our study examined a central developmental mystery: the locus of developmental change that ushers in continuous "background" activity, the basis of cortical states, and their modulation by arousal and vigilance. For primary visual thalamocortex of rats, we show that the emergence of both continuity and one component of arousal modulation, movement- associated increases in firing, occurs simultaneously in both structures between $\mathrm{P} 11$ and P13, just before eye opening. Activity in dLGN is necessary to maintain continuous activity and its modulation by movement in VC from eye opening to adulthood, whereas cortical activity is not necessary for either in dLGN after P13. Thus, continuity of activity and its robust modulation by behavioral state arises during development not because of circuit changes in VC, or within the thalamocortical loop, but through the acquisition of both within dLGN and/or its inputs. The simultaneous emergence of both continuity and state-modulation suggests they are driven by the same mechanisms. This mechanism is not thalamic bursting, which emerges 3 d later. Finally, we further implicate circuit changes within dLGN as the locus for the rapid decrease in excitability to visual stimuli that occurs simultane- 
A

$$
\text { v stim }
$$
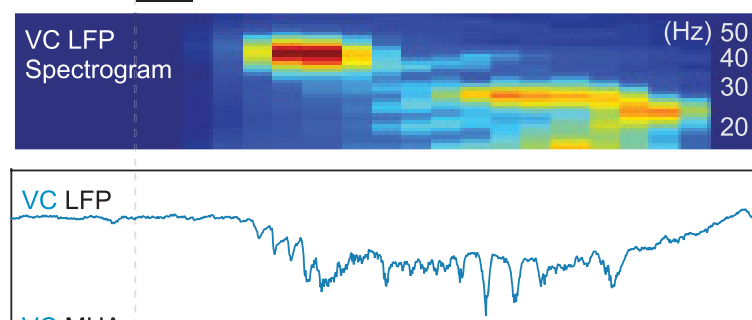

VC MUA

| || || |||||||||||||||||||||||||||||| | | | || || || || ||||||||||||

dLGN MUA

dLGN LFP

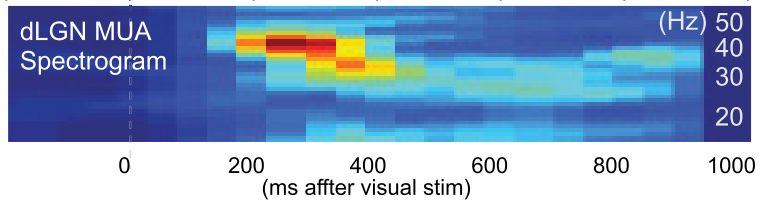

B

$$
\prod_{\text {vstim }}^{\infty} P 13
$$

VC LFP

Spectrogram

( $\mathrm{Hz}) 50$

40

20
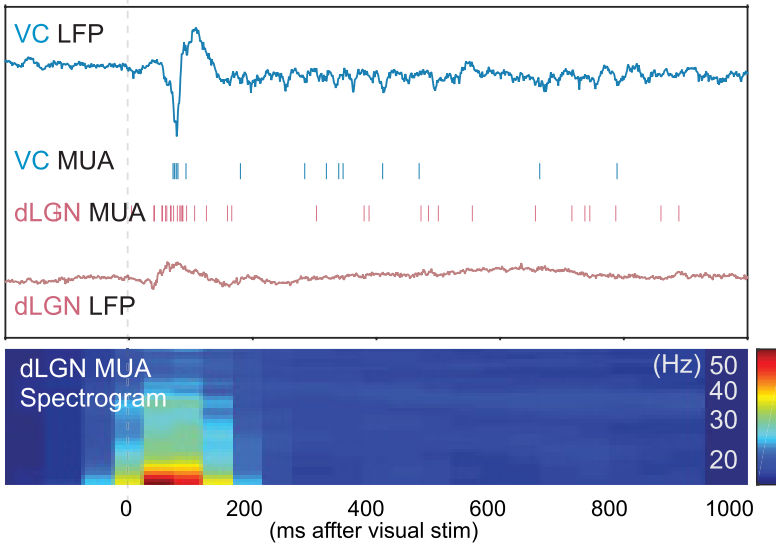

C VC Spike Response
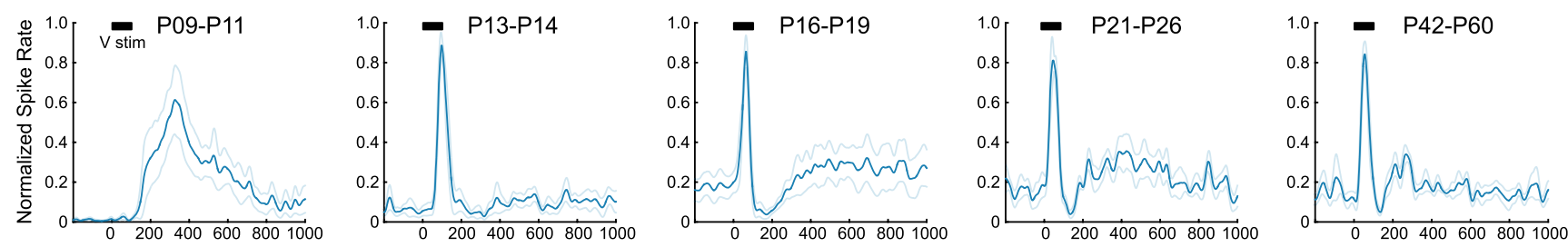

\section{D dLGN Spike Response}
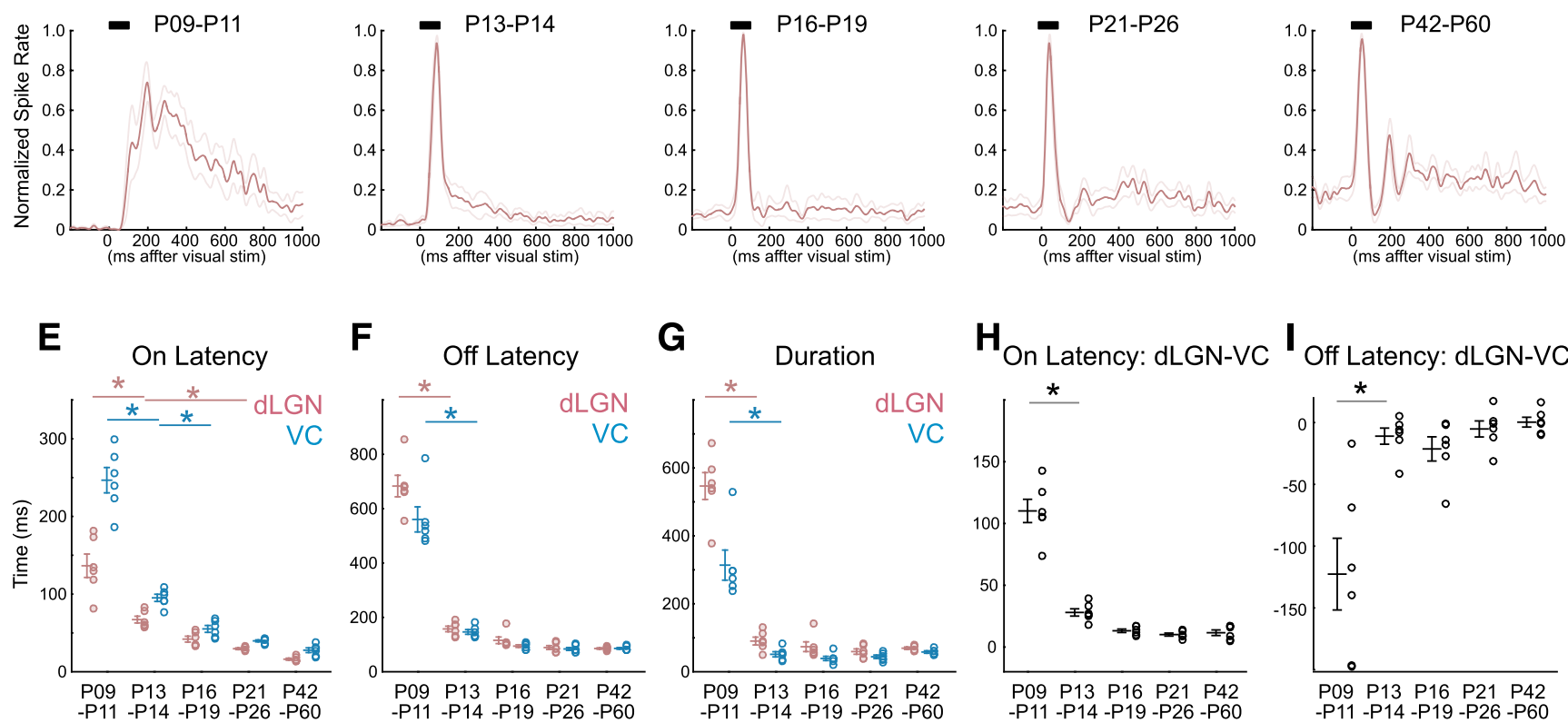

Figure 7. Thalamocortical visual responses and transmission mature simultaneously with spontaneous activity. $\boldsymbol{A}, \boldsymbol{B}$, Representative visual response in simultaneously recorded VC and dLGN of awake rats at P10 (A) and P13 (B). LFP, MUA, and spectrogram of VC LFP and dLGN MUA are shown in response to $100 \mathrm{~ms}$ whole-field light flash onto the contralateral eye. At P10, both dLGN MUA and VC LFP generate initial early-gamma oscillation and subsequent spindle-burst oscillation ( $A)$. At P13, even though the eyelids are still closed at this age, both dLGN and VC show a faster and shorter visual spike response and no longer generate long-lasting beta and gamma oscillation (B). C, D, Population mean poststimulus spike rate histogram for P9-P11, P13-P14, P16-P19, P21-P26, and P42-P60 in VC (C) and dLGN (D). Thin lines show SEM. $\boldsymbol{E}-\boldsymbol{I}$, Thalamocortical visual response and transmission largely improve between P11 and P13 when spontaneous activity also matures. Population mean of on latency $(\boldsymbol{E})$, off latency $(\boldsymbol{F})$, duration $(\boldsymbol{G})$, on latency between dLGN and VC $(\boldsymbol{H})$, and off latency between dLGN and VC $(\boldsymbol{I})$ for each age $(n=6$ for each, ANOVA, horizontal bar shows shortest significant difference; $\left.{ }^{*} p<0.05\right)$. 
ously with spontaneous activity in rodents, ferrets, and humans (Smith et al., 2015; Li et al., 2017; Colonnese and Phillips, 2018). Together, our results show that for the visual system, relay thalamus plays an unexpectedly important role as a central pacer of activity development in cortex, and may provide crucial clues to the mechanism of action of developmental insults, such as severe infection and hypoxia/ischemia, which disrupt the development of continuous activity to disastrous effect (André et al., 2010; Iyer et al., 2014; Benders et al., 2015; Ranasinghe et al., 2015). Animal models systemically mimicking common brain injuries, such as thalamic or white-matter lesions after hypoxic-ischemic encephalopathy (McQuillen and Ferriero, 2004; Miller et al., 2005; Rutherford et al., 2010), have the potential to inform the circuit basis of disrupted EEG and improve diagnosis of infants in vulnerable situations.

\section{LGN is the locus for the acquisition of mature background activity in $\mathrm{VC}$}

During the period of initial thalamic axon growth and cortical circuit formation, spontaneous activity generated within thalamocortical circuits is minimal (Colonnese and Khazipov, 2012; Ackman and Crair, 2014; Leighton and Lohmann, 2016). Instead, activation is largely provided by inputs to thalamus. This input comes from spontaneous bursts in the sense organ in primary sensory and motor cortex, and hippocampus in frontal association regions (An et al., 2014; Del Rio-Bermudez et al., 2015; Hartung et al., 2016; Luhmann and Khazipov, 2018). Because modulation of continuous, internally generated thalamocortical activity is the basis of the commonly described cortical vigilance states (McCormick et al., 2015), its absence in early development contributes to the poor and atypical state regulation of cortical activity observed during the early development of all mammalian species (Jouvet-Mounier et al., 1970; Marcano-Reik and Blumberg, 2008; Seelke and Blumberg, 2010). As measured by the electrocardiogram and EMG, neonates cycle through wake and sleep states similar to those found in adults (Blumberg et al., 2014; Dereymaeker et al., 2017). Furthermore, the midbrain and hindbrain nuclei regulating arousal behave similarly in infants and adults (Karlsson and Blumberg, 2005). Thus acquisition of cortical activity regulation by behavioral and brainstem arousal awaits integration of thalamocortex into the ascending activating and sleep-regulatory systems, not the development of these systems per se. For example, during the first 2 postnatal weeks VC neurons (and network) do not produce an "active" ("Up") state either during sleep or wakefulness, but on P13 they express both persistent stable depolarization during wakefulness as well as alternating up- and down-states during sleep, as if the mechanisms shifting cortex between waking and sleep were intact but they lacked a target to modulate (Colonnese, 2014).

The present results significantly extend our understanding of this process by identifying, for visual thalamocortex at least, changes within relay thalamus as its locus. Recent work has indicated a critical role for thalamus in the maintenance of continuous activity during waking and sleep in adults (Lemieux et al., 2014; Reinhold et al., 2015). Our results show that what is missing during early development of VC is not the capacity to respond to spontaneous activity in dLGN, or to changes in the circuitry or activity of cortical feedback, but rather the capacity of relay thalamus itself to generate continuous and state-dependent activity.

The specific circuit changes within dLGN that drive these processes remains unclear. Increasing continuity of retinal background activity likely contributes. In mice, spontaneous (discontinuous) waves of retinal ganglion cells transition to con- tinuous, response-type-specific patterns during the third postnatal week (Demas et al., 2003). In adult cats, the large majority of spontaneous dLGN activity is driven by retina, but dLGN quickly recovers spontaneous activity after retinal lesions suggesting that intrinsic excitability of dLGN relay cells can contribute to regulation of spontaneous firing and may play a factor in its development (Eysel and Grüsser, 1978). The capacity of dLGN to maintain activity via interactions between the thalamic reticular nucleus (TRN) and cortex via hyperpolarization-activated currents and bursting is a potential contributor to the development of continuity, as many of the anatomical and cellular components are developing during the second and third postnatal weeks. (Lo et al., 2002; Bickford et al., 2010; Dilger et al., 2011).

Perhaps more likely to be a thalamic effect, is the development of movement-associated increases in firing at P13. Surprisingly, we find that activity in thalamus is required for positive modulation by movement in VC after P13. Recent studies show that VC firing is increased during running, although similar spike-rate modulation in dLGN has received mixed evidence (Niell and Stryker, 2010; Erisken et al., 2014; Williamson et al., 2015; Roth et al., 2016). We found increases in dLGN firing during movement larger than previously identified on a running wheel. This may be due to species (rat vs mouse), behavioral protocol (tube restrained vs running), or visual stimulus (low-light vs defined visual stimulus; Dipoppa et al., 2018). We note that the amplitude of the movement effect at the single-unit level is decreasing with age and thus may be more similar to others' results after P60. More surprising, we show that in the absence of dLGN, VC firing is suppressed, as in neonates. This is reminiscent of the barrel cortex, where whisking causes suppression of cortical activation when thalamus is silenced (Poulet et al., 2012; but see Constantinople and Bruno, 2011). Our results are not consist with a simple model of cortical disinhibition causing movement-associated firing (Fu et al., 2014), but rather a more complex, and stimulusdependent (Pakan et al., 2016; Dipoppa et al., 2018) rebalancing of recurrent and thalamic inputs within the cortical network.

\section{Early bursting and visual responses}

Interestingly, thalamic bursting is not a critical component of the initial development of cortical state modulation, or the downregulation of visual responses. The various low frequencies produced during the various states of quiescence arise through a complicated interaction between thalamic and cortical oscillators (Crunelli et al., 2015), with relay neuron bursting working to entrain cortical slow-waves (David et al., 2013). The cortical behavior most correlated to the emergence of thalamic bursting in our data were a shift in the peak frequency during quiescence from 3 to $6 \mathrm{~Hz}$. Our data are consistent with a model of development in which at P13 the acquisition of continuous activity in dLGN drives continuous activity in VC; the density of this activity is low during quiescence resulting in slow-wave generated largely in cortex dominating the LFP, whereas during movement dLGN activity is denser, resulting in a continuous up-state (Colonnese, 2014). By P16 busting allows synchronization with thalamus, increasing the frequency of "slow" activity in VC.

The changes in visual response properties may revolve around the development of thalamic inhibition and its regulation of calcium dynamics in relay neurons. Plateau potentials could contribute to generation of light-evoked spindle-burst oscillations in dLGN during the early period. In slices the developmental loss of plateau potentials in response to optic nerve stimulation is driven by maturation of inhibition (Dilger et al., 2011). Potential sources of inhibition in dLGN in vivo include both thalamic re- 
ticular nucleus and local dLGN interneurons (Arcelli et al., 1997; Hirsch et al., 2015). Recent studies show that arousal modulates TRN activity (Halassa et al., 2014) and visual attention controls dLGN activity in visual TRN (Wimmer et al., 2015), suggesting various roles of thalamic inhibitory system in adults and possibly also in early development. We recently showed that functional inhibition of the dLGN by VC, presumably through TRN, develops on P13 (Murata and Colonnese, 2016), suggesting that it is likely to contribute to the shortening of visual responses and suppression of plateau potentials. Inhibition is critical to stabilize network activity, allowing for continuous asynchronous activation observed beginning $\sim$ P13 in our animals. Therefore, we suggest that inhibitory development, which is also observed in VC beginning at P13 (Colonnese, 2014), is an important contributor to the development of continuity and adult-like movement-associations observed here.

\section{References}

Ackman JB, Crair MC (2014) Role of emergent neural activity in visual map development. Curr Opin Neurobiol 24:166-175. CrossRef Medline

Ackman JB, Burbridge TJ, Crair MC (2012) Retinal waves coordinate patterned activity throughout the developing visual system. Nature 490:219225. CrossRef Medline

An S, Kilb W, Luhmann HJ (2014) Sensory-evoked and spontaneous gamma and spindle bursts in neonatal rat motor cortex. J Neurosci 34 : 10870-10883. CrossRef Medline

André M, Lamblin MD, d'Allest AM, Curzi-Dascalova L, MoussalliSalefranque F, S Nguyen The T, Vecchierini-Blineau MF, Wallois F, Walls-Esquivel E, Plouin P (2010) Electroencephalography in premature and full-term infants. developmental features and glossary. Neurophysiol Clin 40:59-124. CrossRef Medline

Arcelli P, Frassoni C, Regondi MC, De Biasi S, Spreafico R (1997) GABAergic neurons in mammalian thalamus: a marker of thalamic complexity? Brain Res Bull 42:27-37. CrossRef Medline

Ayaz A, Saleem AB, Schölvinck ML, Carandini M (2013) Locomotion controls spatial integration in mouse visual cortex. Curr Biol 23:890-894. CrossRef Medline

Benders MJ, Palmu K, Menache C, Borradori-Tolsa C, Lazeyras F, Sizonenko S, Dubois J, Vanhatalo S, Hüppi PS (2015) Early brain activity relates to subsequent brain growth in premature infants. Cereb Cortex 25:30143024. CrossRef Medline

Bennett C, Arroyo S, Hestrin S (2013) Subthreshold mechanisms underlying state-dependent modulation of visual responses. Neuron 80:350-357. CrossRef Medline

Berzhanskaya J, Phillips MA, Gorin A, Lai C, Shen J, Colonnese MT (2017) Disrupted cortical state regulation in a rat model of fragile $\mathrm{X}$ syndrome. Cereb Cortex 27:1386-1400. CrossRef Medline

Bickford ME, Slusarczyk A, Dilger EK, Krahe TE, Kucuk C, Guido W (2010) Synaptic development of the mouse dorsal lateral geniculate nucleus. J Comp Neurol 518:622-635. CrossRef Medline

Blumberg MS, Gall AJ, Todd WD (2014) The development of sleep-wake rhythms and the search for elemental circuits in the infant brain. Behav Neurosci 128:250-263. CrossRef Medline

Brooks JM, Su J, Levy C, Wang JS, Seabrook TA, Guido W, Fox MA (2013) A molecular mechanism regulating the timing of corticogeniculate innervation. Cell Rep 5:573-581. CrossRef Medline

Chen G, Rasch MJ, Wang R, Zhang XH (2015) Experience-dependent emergence of beta and gamma band oscillations in the primary visual cortex during the critical period. Sci Rep 5:17847. CrossRef Medline

Cohen MX (2014) Analyzing neural time series data. Cambridge, MA: MIT.

Colonnese M, Khazipov R (2012) Spontaneous activity in developing sensory circuits: implications for resting state fMRI. Neuroimage 62:22122221. CrossRef Medline

Colonnese MT (2014) Rapid developmental emergence of stable depolarization during wakefulness by inhibitory balancing of cortical network excitability. J Neurosci 34:5477-5485. CrossRef Medline

Colonnese MT, Khazipov R (2010) "Slow activity transients" in infant rat visual cortex: a spreading synchronous oscillation patterned by retinal waves. J Neurosci 30:4325-4337. CrossRef Medline

Colonnese MT, Phillips MA (2018) Thalamocortical function in developing sensory circuits. Curr Opin Neurobiol 52:72-79. CrossRef Medline
Colonnese MT, Kaminska A, Minlebaev M, Milh M, Bloem B, Lescure S, Moriette G, Chiron C, Ben-Ari Y, Khazipov R (2010) A conserved switch in sensory processing prepares developing neocortex for vision. Neuron 67:480-498. CrossRef Medline

Colonnese MT, Shen J, Murata Y (2017) Uncorrelated neural firing in mouse visual cortex during spontaneous retinal waves. Front Cell Neurosci 11:289. CrossRef Medline

Constantinople CM, Bruno RM (2011) Effects and mechanisms of wakefulness on local cortical circuits. Neuron 69:1061-1068. CrossRef Medline

Crunelli V, David F, Lőrincz ML, Hughes SW (2015) The thalamocortical network as a single slow wave-generating unit. Curr Opin Neurobiol 31:72-80. CrossRef Medline

David F, Schmiedt JT, Taylor HL, Orban G, Di Giovanni G, Uebele VN, Renger JJ, Lambert RC, Leresche N, Crunelli V (2013) Essential thalamic contribution to slow waves of natural sleep. J Neurosci 33:19599_ 19610. CrossRef Medline

Demas J, Eglen SJ, Wong ROL (2003) Developmental loss of synchronous spontaneous activity in the mouse retina is independent of visual experience. J Neurosci 23:2851-2860. CrossRef Medline

Dereymaeker A, Pillay K, Vervisch J, De Vos M, Van Huffel S, Jansen K, Naulaers G (2017) Review of sleep-EEG in preterm and term neonates. Early Hum Dev 113:87-103. CrossRef Medline

Dilger EK, Shin HS, Guido W (2011) Requirements for synaptically evoked plateau potentials in relay cells of the dorsal lateral geniculate nucleus of the mouse. J Physiol 589:919-937. CrossRef Medline

Dipoppa M, Ranson A, Krumin M, Pachitariu M, Carandini M, Harris KD (2018) Vision and locomotion shape the interactions between neuron types in mouse visual cortex. Neuron 98:602-615.e8. CrossRef Medline

Erisken S, Vaiceliunaite A, Jurjut O, Fiorini M, Katzner S, Busse L (2014) Effects of locomotion extend throughout the mouse early visual system. Curr Biol 24:2899-2907. CrossRef Medline

Eysel UT, Grüsser OJ (1978) Increased transneuronal excitation of the cat lateral geniculate nucleus after acute deafferentation. Brain Res 158:107128. CrossRef Medline

Fiser J, Chiu C, Weliky M (2004) Small modulation of ongoing cortical dynamics by sensory input during natural vision. Nature 431:573-578. CrossRef Medline

Fox MD, Raichle ME (2007) Spontaneous fluctuations in brain activity observed with functional magnetic resonance imaging. Nat Rev Neurosci 8:700-711. CrossRef Medline

Fu Y, Tucciarone JM, Espinosa JS, Sheng N, Darcy DP, Nicoll RA, Huang ZJ, Stryker MP (2014) A cortical circuit for gain control by behavioral state. Cell 156:1139-1152. CrossRef Medline

Gramsbergen A (1976) The development of the EEG in the rat. Dev Psychobiol 9:501-515. CrossRef Medline

Grant E, Hoerder-Suabedissen A, Molnár Z (2012) Development of the corticothalamic projections. Front Neurosci 6:53. CrossRef Medline

Halassa MM, Chen Z, Wimmer RD, Brunetti PM, Zhao S, Zikopoulos B, Wang F, Brown EN, Wilson MA (2014) State-dependent architecture of thalamic reticular subnetworks. Cell 158:808-821. CrossRef Medline

Hanganu IL, Ben-Ari Y, Khazipov R (2006) Retinal waves trigger spindle bursts in the neonatal rat visual cortex. J Neurosci 26:6728-6736. CrossRef Medline

Harris KD, Thiele A (2011) Cortical state and attention. Nat Rev Neurosci 12:509-523. CrossRef Medline

Hartung H, Cichon N, De Feo V, Riemann S, Schildt S, Lindemann C, Mulert C, Gogos JA, Hanganu-Opatz IL (2016) From shortage to surge: a developmental switch in hippocampal-prefrontal coupling in a gene-environment model of neuropsychiatric disorders. Cereb Cortex 26:4265-4281. CrossRef Medline

Hirsch JA, Wang X, Sommer FT, Martinez LM (2015) How inhibitory circuits in the thalamus serve vision. Annu Rev Neurosci 38:309-329. CrossRef Medline

Holmes GL, Lombroso CT (1993) Prognostic value of background patterns in the neonatal EEG. J Clin Neurophysiol 10:323-352. CrossRef Medline

Hong YK, Chen C (2011) Wiring and rewiring of the retinogeniculate synapse. Curr Opin Neurobiol 21:228-237. CrossRef Medline

Hoy JL, Niell CM (2015) Layer-specific refinement of visual cortex function after eye opening in the awake mouse. J Neurosci 35:3370-3383. CrossRef Medline

Huberman AD, Feller MB, Chapman B (2008) Mechanisms underlying development of visual maps and receptive fields. Annu Rev Neurosci 31: 479-509. CrossRef Medline 
Iyer KK, Roberts JA, Metsäranta M, Finnigan S, Breakspear M, Vanhatalo S (2014) Novel features of early burst suppression predict outcome after birth asphyxia. Ann Clin Transl Neurol 1:209-214. CrossRef Medline

Jouvet-Mounier D, Astic L, Lacote D (1970) Ontogenesis of the states of sleep in rat, cat, and guinea pig during the first postnatal month. Dev Psychobiol 2:216-239. CrossRef Medline

Karlsson KÆ, Blumberg MS (2003) Hippocampal theta in the newborn rat is revealed under conditions that promote REM sleep. J Neurosci 23: 1114-1118. CrossRef Medline

Karlsson KÆ, Blumberg MS (2005) Active medullary control of atonia in week-old rats. Neuroscience 130:275-283. CrossRef Medline

Khazipov R, Luhmann HJ (2006) Early patterns of electrical activity in the developing cerebral cortex of humans and rodents. Trends Neurosci 29: 414-418. CrossRef Medline

Khazipov R, Colonnese M, Minlebaev M (2013) Neonatal cortical rhythms. In: Neural circuit development and function in the brain, Chap 8 (Rubenstein JLR, Rakic P, eds.), pp 131-153. Oxford, UK: Academic.

Khazipov R, Zaynutdinova D, Ogievetsky E, Valeeva G, Mitrukhina O, Manent JB, Represa A (2015) Atlas of the postnatal rat brain in stereotaxic coordinates. Front Neuroanat 9:161. CrossRef Medline

Lee AM, Hoy JL, Bonci A, Wilbrecht L, Stryker MP, Niell CM (2014) Identification of a brainstem circuit regulating visual cortical state in parallel with locomotion. Neuron 83:455-466. CrossRef Medline

Leighton AH, Lohmann C (2016) The wiring of developing sensory circuits: from patterned spontaneous activity to synaptic plasticity mechanisms. Front Neural Circuits 10:71. CrossRef Medline

Lemieux M, Chen JY, Lonjers P, Bazhenov M, Timofeev I (2014) The impact of cortical deafferentation on the neocortical slow oscillation. J Neurosci 34:5689-5703. CrossRef Medline

Li Y, Yu C, Zhou ZC, Stitt I, Sellers KK, Gilmore JH, Frohlich F (2017) Early development of network oscillations in the ferret visual cortex. Sci Rep 7:17766. CrossRef Medline

Llinás RR, Steriade M (2006) Bursting of thalamic neurons and states of vigilance. J Neurophysiol 95:3297-3308. CrossRef Medline

Lo FS, Ziburkus J, Guido W (2002) Synaptic mechanisms regulating the activation of a $\mathrm{Ca}^{2+}$-mediated plateau potential in developing relay cells of the LGN. J Neurophysiol 87:1175-1185. CrossRef Medline

Luhmann HJ, Khazipov R (2018) Neuronal activity patterns in the developing barrel cortex. Neuroscience 368:256-267. CrossRef Medline

Marcano-Reik AJ, Blumberg MS (2008) The corpus callosum modulates spindle-burst activity within homotopic regions of somatosensory cortex in newborn rats. Eur J Neurosci 28:1457-1466. CrossRef Medline

McCormick DA, McGinley MJ, Salkoff DB (2015) Brain state dependent activity in the cortex and thalamus. Curr Opin Neurobiol 31:133-140. CrossRef Medline

McQuillen PS, Ferriero DM (2004) Selective vulnerability in the developing central nervous system. Pediatr Neurol 30:227-235. CrossRef Medline

Miller SP, Ramaswamy V, Michelson D, Barkovich AJ, Holshouser B, Wycliffe N, Glidden DV, Deming D, Partridge JC, Wu YW, Ashwal S, Ferriero DM (2005) Patterns of brain injury in term neonatal encephalopathy. J Pediatr 146:453-460. CrossRef Medline

Mitra P, Bokil H (2007) Observed brain dynamics. Oxford, UK; New York: Oxford UP.

Mukherjee D, Yonk AJ, Sokoloff G, Blumberg MS (2017) Wakefulness suppresses retinal wave-related neural activity in visual cortex. J Neurophysiol 118:1190-1197. CrossRef Medline

Murata Y, Colonnese MT (2016) An excitatory cortical feedback loop gates retinal wave transmission in rodent thalamus. eLife 5:e18816. CrossRef Medline

Niell CM, Stryker MP (2010) Modulation of visual responses by behavioral state in mouse visual cortex. Neuron 65:472-479. CrossRef Medline

Pakan JM, Lowe SC, Dylda E, Keemink SW, Currie SP, Coutts CA, Rochefort NL (2016) Behavioral-state modulation of inhibition is contextdependent and cell type specific in mouse visual cortex. eLife 5:e14985. CrossRef Medline

Polack PO, Friedman J, Golshani P (2013) Cellular mechanisms of brain state-dependent gain modulation in visual cortex. Nat Neurosci 16:13311339. CrossRef Medline

Poulet JFA, Fernandez LM, Crochet S, Petersen CC (2012) Thalamic control of cortical states. Nat Neurosci 15:370-372. CrossRef Medline

Ranasinghe S, Or G, Wang EY, Ievins A, McLean MA, Niell CM, Chau V, Wong PK, Glass HC, Sullivan J, McQuillen PS (2015) Reduced cortical activity impairs development and plasticity after neonatal hypoxia ischemia. J Neurosci 35:11946-11959. CrossRef Medline

Reinhold K, Lien AD, Scanziani M (2015) Distinct recurrent versus afferent dynamics in cortical visual processing. Nat Neurosci 18:1789-1797. CrossRef Medline

Del Rio-Bermudez C, Sokoloff G, Blumberg MS (2015) Sensorimotor processing in the newborn rat red nucleus during active sleep. J Neurosci 35:8322-8332. CrossRef Medline

van Rooij LG, Toet MC, Osredkar D, van Huffelen AC, Groenendaal F, de Vries LS (2005) Recovery of amplitude integrated electroencephalographic background patterns within 24 hours of perinatal asphyxia. Arch Dis Child Fetal Neonatal Ed 90:F245-FF251. CrossRef Medline

Rossant C, Kadir SN, Goodman DFM, Schulman J, Hunter MLD, Saleem AB, Grosmark A, Belluscio M, Denfield GH, Ecker AS, Tolias AS, Solomon S, Buzsaki G, Carandini M, Harris KD (2016) Spike sorting for large, dense electrode arrays. Nat Neurosci 19:634-641. CrossRef Medline

Roth MM, Dahmen JC, Muir DR, Imhof F, Martini FJ, Hofer SB (2016) Thalamic nuclei convey diverse contextual information to layer 1 of visual cortex. Nat Neurosci 19:299-307. CrossRef Medline

Rutherford M, Malamateniou C, McGuinness A, Allsop J, Biarge MM, Counsell S (2010) Magnetic resonance imaging in hypoxic-ischaemic encephalopathy. Early Hum Dev 86:351-360. CrossRef Medline

Sakata S, Harris KD (2009) Laminar structure of spontaneous and sensoryevoked population activity in auditory cortex. Neuron 64:404-418. CrossRef Medline

Scher MS (2008) Ontogeny of EEG-sleep from neonatal through infancy periods. Sleep Med 9:615-636. CrossRef Medline

Seabrook TA, El-Danaf RN, Krahe TE, Fox MA, Guido W (2013) Retinal input regulates the timing of corticogeniculate innervation. J Neurosci 33:10085-10097. CrossRef Medline

Seelke AM, Blumberg MS (2008) The microstructure of active and quiet sleep as cortical delta activity emerges in infant rats. Sleep 31:691-699. CrossRef Medline

Seelke AM, Blumberg MS (2010) Developmental appearance and disappearance of cortical events and oscillations in infant rats. Brain Res 1324: 34-42. CrossRef Medline

Sherman SM, Guilery RW (2013) Functional connections of cortical areas. Cambridge, MA: MIT.

Smith GB, Sederberg A, Elyada YM, Van Hooser SD, Kaschube M, Fitzpatrick D (2015) The development of cortical circuits for motion discrimination. Nat Neurosci 18:252-261. CrossRef Medline

Steriade MM, McCarley RW (2005) Brain control of wakefulness and sleep. New York: Springer.

Usrey WM, Alitto HJ (2015) Visual functions of the thalamus. Annu Rev Vis Sci 1:351-371. CrossRef Medline

Vanhatalo S, Kaila K (2006) Development of neonatal EEG activity: from phenomenology to physiology. Semin Fetal Neonatal Med 11:471-478. CrossRef Medline

Vinck M, Batista-Brito R, Knoblich U, Cardin JA (2015) Arousal and locomotion make distinct contributions to cortical activity patterns and visual encoding. Neuron 86:740-754. CrossRef Medline

Weyand TG, Boudreaux M, Guido W (2001) Burst and tonic response modes in thalamic neurons during sleep and wakefulness. J Neurophysiol 85:1107-1118. CrossRef Medline

Whitehead K, Pressler R, Fabrizi L (2017) Characteristics and clinical significance of delta brushes in the EEG of premature infants. Clin Neurophysiol Pract 2:12-18. CrossRef

Williamson RS, Hancock KE, Shinn-Cunningham BG, Polley DB (2015) Locomotion and task demands differentially modulate thalamic audiovisual processing during active search. Curr Biol 25:1885-1891. CrossRef Medline

Wimmer RD, Schmitt LI, Davidson TJ, Nakajima M, Deisseroth K, Halassa MM (2015) Thalamic control of sensory selection in divided attention. Nature 526:705-709. CrossRef Medline

Yang JW, Reyes-Puerta V, Kilb W, Luhmann HJ (2016) Spindle bursts in neonatal rat cereb cortex. Neural Plast 2016:3467832. CrossRef Medline

Yüzgeç Ö, Prsa M, Zimmermann R, Huber D (2018) Pupil size coupling to cortical states protects the stability of deep sleep via parasympathetic modulation. Curr Biol 28:392-400.e3. CrossRef Medline

Ziburkus J, Lo FS, Guido W (2003) Nature of inhibitory postsynaptic activity in developing relay cells of the lateral geniculate nucleus. J Neurophysiol 90:1063-1070. CrossRef 